\title{
Functional Differences in the Neural Substrates of Auditory Cognition as a Consequence of Music Training
}

Naomi du Bois ${ }^{a^{*}}$, José M. Sanchez Bornot ${ }^{a}$, Dheeraj Rathee ${ }^{a}$ b, KongFatt Wong-Lin ${ }^{a}$, Mark A. Elliott ${ }^{c}$, and Girijesh Prasad ${ }^{a}$

${ }^{a}$ Intelligent Systems Research Centre, University of Ulster, Magee Campus, Derry, NI, UK

${ }^{\mathrm{b}}$ School of Computer Science and Electronic Engineering, University of Essex, Colchester, UK

c School of Psychology, National University of Ireland, Galway, Republic of Ireland

* Corresponding author: Naomi du Bois

Corresponding author's present affiliation: Intelligent Systems Research Centre, University of Ulster, Magee Campus, Derry, NI, UK

E: n.du-bois@ulster.ac.uk 
bioRxiv preprint doi: https://doi.org/10.1101/2021.06.03.446932; this version posted June 3, 2021. The copyright holder for this preprint

(which was not certified by peer review) is the author/funder, who has granted bioRxiv a license to display the preprint in perpetuity. It is made available under aCC-BY-NC-ND 4.0 International license.

\section{Graphical Abstract}

\section{Functional Differences in the Neural Substrates of Auditory Cognition as a Consequence of Music Training}

Naomi du Bois*, José M. Sanchez Bornot, KongFatt Wong-Lin, Mark A. Elliott, and Girijesh Prasad E: n.du-bois@ulster.ac.uk
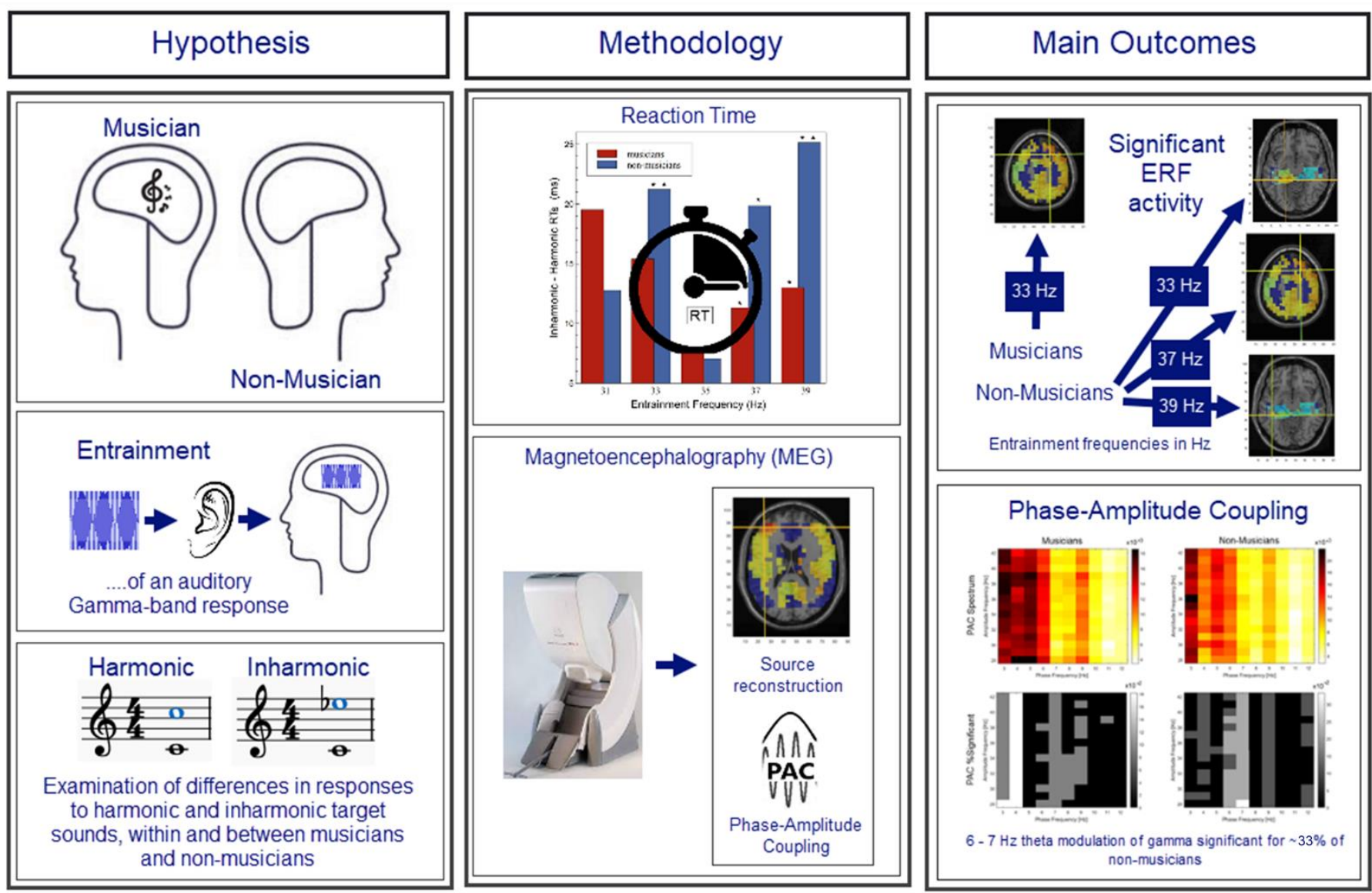

\section{Conclusion}

1. Musicians' auditory cognition relies more on top-down processes, while non-musicians rely on bottomup processing, and therefore, their auditory cognition is facilitated by the entrained gamma-band response.

2. First neural evidence in support of faster reaction-time responses due to an interaction in phase of an entrained gamma-band response of $33 \mathrm{~Hz}$ and a slower endogenous theta rhythm $(\sim 7 \mathrm{~Hz})$ - consistently reported in previous research. 


\begin{abstract}
Previous studies have demonstrated that musical deviants (syntactically irregular chords) elicit event related potentials/fields with negative polarity; specifically, the early right anterior negativity and the right anterior temporal negativity responses with peak latencies at $\sim 200 \mathrm{~ms}$ and $\sim 350 \mathrm{~ms}$, respectively, post stimulus onset. Here, we investigated differences in the neural dynamics of the auditory perceptual system of individuals with music training compared to those with no music training. Magnetoencephalography was used to examine the neural response to a deviant sound when the auditory system was primed using stimulus entrainment to evoke an auditory gamma-band response between $31 \mathrm{~Hz}$ and $39 \mathrm{~Hz}$, in $2 \mathrm{~Hz}$ steps. Participants responded to the harmonic relationship between the entrainment stimulus and the subsequent target stimulus. Gamma frequencies carry stimulus information; thus, the paradigm primed the auditory system with a known gamma frequency and evaluated any improvement in the brains response to a deviant stimulus. The entrainment stimuli did not elicit an early right anterior negativity response. Furthermore, the source location of the eventrelated field difference during the later right anterior temporal negativity response time-window varied depending on group and entrainment condition. In support of previous findings from research using this, and a functionally similar visual-priming paradigm, a $7 \mathrm{~Hz}$ phase modulation of gamma amplitude was found for non-musicians following $33 \mathrm{~Hz}$ stimulus entrainment. Overall, significant effects of gamma entrainment were found more frequently in the non-music brain. By contrast, musicians demonstrated a greater range of interactions with slower brain rhythms, indicative of increased top-down control.
\end{abstract}

Keywords: Music cognition, Entrainment, Early right anterior negativity (ERAN), Right anterior temporal negativity (RATN), Auditory gamma-band response (aGBR), Phase-amplitude coupling (PAC) 
bioRxiv preprint doi: https://doi.org/10.1101/2021.06.03.446932; this version posted June 3, 2021. The copyright holder for this preprint (which was not certified by peer review) is the author/funder, who has granted bioRxiv a license to display the preprint in perpetuity. It is made available under aCC-BY-NC-ND 4.0 International license.

EFFECTS OF MUSIC TRAINING ON AUDITORY COGNITIVE PROCESSES

\section{Introduction}

Music perception relies on several processes to decode the acoustic information present in the auditory scene such as musical syntax and semantics. These processes include auditory memory and extend to stimulating pre-motor representations of action (Koelsch, 2011). Music cognition is the area of research involved in determining the cortical processes underlying music perception (Justus \& Bharucha, 2002). Predictably, musicians, through their training, have developed more efficient cortical mechanisms to subserve these processes. The acquisition of a skill necessarily results in structural and functional changes in the brain to optimise the processes involved in the performance of that skill over time ( $\mathrm{Pi}$ et al., 2019; Rosenberg-Lee et al., 2018). Regarding harmonic and melodic prediction, neurophysiological music research has demonstrated that syntactically irregular chords elicit eventrelated potentials (ERPs) with negative polarity and peak latencies of around 150-350 ms poststimulus onset (Rohrmeier \& Koelsch, 2012). The early right anterior negativity (ERAN), and the right anterior temporal negativity (RATN) responses are passively evoked responses, elicited by musical syntax violations. The former arises $\sim 150 \mathrm{~ms}$ post-stimulus onset in electroencephalography (EEG) recordings and $\sim 200 \mathrm{~ms}$ in magnetoencephalography (MEG) recordings, while the latter arises $\sim 300$ ms post-stimulus onset in EEG recordings and 350 ms in MEG recordings, (Maess, Koelsch, Gunter, \& Friederici, 2001; Rohrmeier \& Koelsch, 2012). Both the ERAN and RATN response are measured as the difference in cortical activation in response to deviant tones compared to a standard tone. The former is elicited by violations in musical syntax, while the latter occurs when the position of an irregular tone structure within a sequence is unknown, or unpredictable. The RATN response is associated with applying syntactical rules (Koelsch \& Mulder, 2002). Given the large body of research documenting structural and functional differences in musicians' brains compared to their nonmusician peers (Angulo-Perkins et al., 2014; Gaser \& Schlaug, 2003; Schlaug et al., 1995; Schneider et al., 2005; Zatorre et al., 2007) - a comparison of the music versus the non-music brain provides an excellent means to examine the oscillatory mechanisms involved in auditory binding.

The auditory-priming paradigm used in the current study, to investigate differences in these oscillatory mechanisms as a result of neural plasticity due to music training, was originally designed by Aksentijevic et al. (2011), for the examination of frequency and phase interactions involved in topdown modulation of the oscillatory neural mechanisms that amplify or attenuate incoming stimulus information. The stimuli used in this paradigm are pip-train stimuli, which are effectively short bursts of pure tones that are amplitude modulated, with the amplitude modulation (AM) frequency determined by the duration of the pip, i.e., a pip duration of $25 \mathrm{~ms}$ is equivalent to an AM frequency of $40 \mathrm{~Hz}$. Galambos, Makeig, \& Talmachoff (1981) discovered when 25 ms pips (which were referred to as 'clicks') of different frequencies [250,350, and $500 \mathrm{~Hz}$ ] were presented repeatedly to the auditory system, a stable composite $40-\mathrm{Hz}$ event-related potential (ERP) was evoked $8-80 \mathrm{~ms}$ post-stimulus onset, that was phase locked to the auditory stimulus which produced the response - termed an auditory (evoked) gamma-band-response (aGBR - see Aksentijevic et al., 2013, 2014; Robert Galambos, 1992). Importantly, a feature of pip-trains is that each pip can carry a different frequency, meaning the carrier frequency (CF) can change with each cycle of the AM frequency. The Aksentijevic et al. (2011) paradigm used these characteristics of pip-train stimuli to establish an entrained aGBR in auditory cortex of a known gamma-band frequency (regulated by the AM of the pip-train), and subsequently examined the frequency-specific effects this had on reaction-time (RT) responses to tones that are either consonant or dissonant with the entrainer pip-trains CFs. Therefore, research using this paradigm refers to the AM frequency as the entrainment frequency. In the paradigm 
bioRxiv preprint doi: https://doi.org/10.1101/2021.06.03.446932; this version posted June 3, 2021. The copyright holder for this preprint (which was not certified by peer review) is the author/funder, who has granted bioRxiv a license to display the preprint in perpetuity. It is made available under aCC-BY-NC-ND 4.0 International license.

designed by Aksentijevic et al. (2011) two pip-train stimuli are presented separated by a brief (100 ms) inter-stimulus interval (ISI). Both share the same entrainment frequency (in the gamma range). The first pip-train is the entrainer stimulus and carries a repeated four-pip sequence of a single $1000 \mathrm{~Hz}$ (deviant) pip followed by three $500 \mathrm{~Hz}$ (baseline) pips. The pip-train that follows is the target stimulus, of which there are three types defined by the structure and the harmonic relations between the entrainer and the target - the relation is determined by the interval between the targets deviant CF of $1000 \mathrm{~Hz}$ and the entrainers deviant CF. The target absent stimulus contains a single CF of $1000 \mathrm{~Hz}$ - thus, there is no interval between this and the entrainer's deviant CF - the tonal pattern is flat, and the target is absent. A harmonic target has CFs that alternate between a $1000 \mathrm{~Hz}$ (baseline) and a 2000 $\mathrm{Hz}$ (deviant) - as $2000 \mathrm{~Hz}$ is the first harmonic of $1000 \mathrm{~Hz}$, this interval difference is harmonic. An inharmonic target has CFs that alternate between $1000 \mathrm{~Hz}$ (baseline) and $2400 \mathrm{~Hz}$ (deviant) CFs - as the deviant frequencies in this case are separated by an octave plus a minor third, the interval difference is inharmonic. Both the harmonic and the inharmonic are referred to as target present conditions given the presence of a deviant CF that bears a harmonic relation to the CFs of the entrainment stimuli (see Aksentijevic et al. 2014 for details). Participants are asked to passively listen to the entrainer and then make a speeded response to the target pip train - 'absent' if it is monotonic (1000 Hz CF only), or 'present' if it has an alternating tonal pattern. The inharmonic violates the listener's expectancy within a harmonic context, in the same way a 'deviant' tone is incongruous compared to a 'standard' tone in an oddball scenario. The target absent condition is not of interest. However, it is easier to make a quick and accurate response to the difference in tonal pattern, thus allowing an examination of pre-attentive processing of harmony relations. Stimulus entrainment prepares the auditory system in two ways. Firstly, the entrainment frequency establishes a phase locked auditory GBR and gamma frequencies are known to be involved in carrying feedforward stimulus information and prediction errors (Fries, 2015; Michalareas et al., 2016). Thus, stimulus entrainment provides this information carrier in advance of the target stimulus. Secondly, the CFs of the entrainment stimuli prepare the auditory system to expect a $1000-\mathrm{Hz}$ harmonic relation.

Aksentijevic et al. (2011) found that responses to inharmonic targets were significantly faster than to harmonic targets, only for an entrainment frequency of $33 \mathrm{~Hz}$ - termed an inharmonic popout'. Moreover, Aksentijevic, Smith and Elliott (2014) found that while musicians respond faster to inharmonic compared to harmonic targets, responses to both target types are faster compared to musically naïve controls - and importantly, the difference between responses to harmonic and inharmonic targets were not significant across a range of entrainment conditions $(29 \mathrm{~Hz}, 31 \mathrm{~Hz}, 33 \mathrm{~Hz}$, $35 \mathrm{~Hz}$, and $37 \mathrm{~Hz}$ ). This means there was no evidence of a pop-out effect among musicians. Gamma oscillatory activity has been linked to experience-dependent plasticity during the learning period and once the associative memory has been acquired, performance is no longer influenced by gamma activity (Headley \& Weinberger, 2011). Aksentijevic and colleagues (2014) refer to these learned harmonic representations as 'harmonic templates' which, once formed, render redundant any reliance on gamma oscillatory binding mechanisms when discriminating harmony relations. Furthermore, the 'pop-out' effect among non-musicians has been found to occur following interstimulus intervals of $\sim 110 \mathrm{~ms}$ and $\sim 260 \mathrm{~ms}$ post-stimulus onset. Therefore, Aksentijevic and colleagues (2011) referred to this as a rate- and time-specific reaction time (RT) advantage. Rate in this context describes the number of pips per second (pps) in the entrainment stimulus and thus is interchangeable with frequency. Given these time-specific advantages are separated by approximately $150 \mathrm{~ms}$, which is the duration of one cycle of a $6.7 \mathrm{~Hz}$ wave, the inference is that the second time advantage was 
bioRxiv preprint doi: https://doi.org/10.1101/2021.06.03.446932; this version posted June 3, 2021. The copyright holder for this preprint (which was not certified by peer review) is the author/funder, who has granted bioRxiv a license to display the preprint in perpetuity. It is made available under aCC-BY-NC-ND 4.0 International license.

mediated by a theta rhythm (see Aksentijevic et al., 2011, 2013 for details). Evidence from research investigating the optimal frequency and phase conditions required to process object information in the visual scene suggests that the facilitation effect found when the visual system is similarly primed with specific frequencies in the lower gamma-band range $(30 \mathrm{~Hz}-70 \mathrm{~Hz})$ is also influenced by the phase relation of an endogenous theta rhythm (for details see Elliott, 2014).

The current research examined evidence for a reduced reliance on bottom-up gammaoscillatory activity due to music training related plasticity effects. Both the ERAN and the RATN response occur during specific time windows post-stimulus onset. However, to date these responses have not been examined under stimulus-entrainment conditions. On this basis, it was hypothesised, given a reduction in reliance on feedforward gamma frequency carriers due to music training, that any effect of stimulus entrainment on the ERAN and RATN responses would be greater for non-musicians than musicians. Just as gamma frequencies have been established as feedforward information carriers, slower brain rhythms (i.e., delta, theta, alpha, and beta) have been found to feedback expected, or predicted, representations (Bubic, Yves von Cramon, \& Schubotz, 2010; Engel, Fries, \& Singer, 2001; Fries, 2015; Michalareas et al., 2016; Sauseng \& Klimesch, 2008). Given previous stimulus entrainment research findings support a gamma-theta interaction that promotes a discriminatory stimulus response, it was further hypothesised that evidence of gamma-theta coupling would be found under entrainment conditions that resulted in improved responses, i.e., a pop-out effect. Thus, the current research aimed to examine the neural mechanisms underlying improved performance in responses to tones that are unexpected, following stimulus entrainment, as suggested by the findings of previous research using this auditory paradigm, and a functionally similar visual paradigm (Aksentijevic et al., 2011, 2014; du Bois \& Elliott, 2017; Elliott, 2014).

\section{Material and methods}

Experimental sessions were conducted in the Northern Ireland Functional Brain Mapping (NIFBM) facility, at the Intelligent Systems Research Centre, Magee Campus, Ulster University, Derry, Northern Ireland. The study was carried out in accordance with the Declaration of Helsinki. Approval was obtained for the study from both the National University of Ireland, Galway Research Ethics Committee and the Ulster University, Research Governance department. Informed consent was provided by participants prior to taking part. Experimental sessions lasted between 60 and 80 minutes.

\section{Participants}

Twenty-three participants recruited in Galway and Northern Ireland took part in the study (musician $n=11$, non-musician $n=12$ ). Musicians held Royal Music Academy certificates to a level of grade 3 or above (grade $8+(x 4)$, grade 6 or $7(x 3)$, and grade 3 or $4(x 4)$ ), or an international equivalent ( $n=11$, six male, $M$ age 32.55 years, $S D$ 14.16). All played at least one instrument, and nine played regularly. Non-musicians did not have experience playing a musical instrument ( $n=12$, all male, $M$ age 37.44 years, SD 9.71). For each participant, sessions began with a 20 -trial practice session. Following preprocessing, analysis of the reaction time (RT) data comprised a sample of 11 musicians and 10 nonmusicians (due to missing trigger information), while the neuroimaging analysis comprised data from 11 musicians and 9 non-musicians (due to insufficient trials for one other non-musician). 


\section{Task paradigm}



Figure 1. Trial sequence for an inharmonic target in the $33 \mathrm{~Hz}$ entrainment condition. The entrainer pip-train for all conditions comprised a repeated pattern of four 'pips'; one pip with a CF of $1000 \mathrm{~Hz}$ (the deviant tone; D) followed by three pips with CFs of $500 \mathrm{~Hz}$ (baseline tones; B). The target-absent pip-train for all conditions carried only $1000 \mathrm{~Hz}$ pips, while the harmonic- and inharmonic-target piptrains were composed of an alternating pattern of two pips; the CFs of the alternating pips were $1000 \mathrm{~Hz}$ (B) and $2000 \mathrm{~Hz}$ (D) in the harmonic target pip-train, and $1000 \mathrm{~Hz}$ (B) and $2400 \mathrm{~Hz}$ (D) in the inharmonic target pip-train. The amplitude modulation frequency in the above example was $33 \mathrm{~Hz}-$ therefore, the $1000 \mathrm{~ms}$ entrainment period ended following a deviant pip in the repeated pattern of four pips (DBBB).

A trial sequence began with a $500 \mathrm{~ms}$ cue (crosshair), followed by presentation of the entrainer pip-train stimulus for a constant period of $1000 \mathrm{~ms}$, then a constant interstimulus interval (ISI) of 100 $\mathrm{ms}$, and finally the target pip-train. The trial ended following a response to the target, or $2000 \mathrm{~ms}$ post-target onset if a response was not made before this time (see Figure 1). Participants were presented with 60 trials per condition which resulted in 1200 trials per participant, $(5 \times 2(2) \times 60=$ 1200). Participants were required to respond as rapidly and as accurately as possible, using dedicated response keys to indicate whether the second of the two presented to pip-trains contained alternating tones (i.e., was a target), or was monotonic (a non-target). Target-absent data, i.e., responses to nontargets, were removed from all analyses as the focus of the research was on automatic functional differences between the auditory cognitive processes of musicians and non-musicians when making harmony judgements.

The parameters of the auditory pip-train stimuli were designed to replicate the stimuli in the paradigm which produced the previous 'pop-out' effect following stimulus entrainment of $33 \mathrm{~Hz}$. Thus, the entrainment frequency range for the current experiment was 31 to $39 \mathrm{~Hz}$ in $2 \mathrm{~Hz}$ steps. Experimental trial plus stimulus and trigger generation were coded in-house using COGENT 2000 and COGENT GRAPHICS (http://www.vislab.ucl.ac.uk/cogent.php) toolboxes running in MATLAB R2016b (Oostenveld, Fries, Maris, \& Schoffelen, 2011). The stimulation PC was a HP xw4600 Workstation.

\section{Trials with incorrect responses}

The percentage number of trials that were incorrectly responded to, was $8.21 \%$ overall. The arcsine of the square root of the proportion of incorrect responses for each condition were analysed showing no significant differences in the production of incorrect responses across participants.

\section{MEG data acquisition}

The continuous raw MEG data was recorded per participant, per block (200 trials) using the superconducting quantum interference device (SQUID) based 306-channel whole head MEG Elekta 
bioRxiv preprint doi: https://doi.org/10.1101/2021.06.03.446932; this version posted June 3, 2021. The copyright holder for this preprint (which was not certified by peer review) is the author/funder, who has granted bioRxiv a license to display the preprint in perpetuity. It is made available under aCC-BY-NC-ND 4.0 International license.

Neuromag TRIUX system (Helsinki, Finland), comprising 204 gradiometers and 102 magnetometers. Head shape was obtained by using a three-dimensional Fastrak digitiser (Polhemus) by acquiring three fiducial (or cardinal) points (nasion and left and right preauricular points) and at least 300 points of the surface of the scalp. In addition, four head position indication (HPI) coils were placed on the subjects' head: two on the mastoids and two on the forehead. The positions of the HPI coils were acquired using the Fastrak device to provide continuous head position estimation during the recording. Ocular movements and cardiac activity were measured for cleaning purposes using four electro-oculography (EOG) electrodes (horizontal, and vertical pairs), and two cardiac muscle electrodes. Signals were digitised with a bandwidth of $0.1 \mathrm{~Hz}$ to $300 \mathrm{~Hz}$ and a sampling rate of 1000 $\mathrm{Hz}$. Sound stimuli were presented binaurally via ER-3A ABR Insert Earphones, and the decibel level was attenuated to 50 SPL, as measured by a Precision Gold (IEC 651 TYPE II) sound level meter (model \#: N05CC). Instructions and a cross to cue the start of each trial were rear-projected onto a $112 \mathrm{~cm}$ screen with a resolution of 10249768 pixels at $60 \mathrm{~Hz}$, using a zero-jitter 3-DLP video projector and lens (RMMSX21G; Victor Company of Japan, Kanagawa, Japan). The screen was placed approximately $120 \mathrm{~cm}$ from the participant, who was seated in the upright position. A bilateral finger response system was used to collect participants RT responses.

Data cleaning and analyses (other than the phase-amplitude coupling (PAC) analysis) were performed using in-house scripts in the Fieldtrip toolbox for Matlab R2016b (Oostenveld et al., 2011). The PAC analysis was performed using the Spatial Parametric Mapping (SPM12) toolbox (Litvak et al., 2011).

\section{Preprocessing}

The continuous raw data were filtered off-line using Max Filter temporal signal space separation (tSSS). Data for each participant were then epoched and preprocessed, removing targetabsent and response error trials and offsetting the samples to account for the delay in sound stimuli presentation. A bandpass filter was used to filter out frequencies above $150 \mathrm{~Hz}$, and a discrete Fourier transform was used to filter out line noise. Separate blocks for each participant were concatenated and resampled from 1000 to 500 samples per second. Trials were manually inspected to remove noisy segments, and the data were checked for trials and channels that were outliers. Squid jump detection was used to identify jumpy channels (a cut-off $z$ score of 25 was used). Channels that were outliers (due to noise) were marked as bad and the remaining bad trials detected were removed. Muscle artifacts were removed (using a cut-off $z$ score of 12), and a final visual inspection was performed. Finally, an independent component analysis (ICA) was performed to identify and remove electro-ocular and electro-cardiac components. The clean data were interpolated to repair channels marked as bad. Data were then averaged across trial conditions, i.e., inharmonic-target present (ITP) by entrainment frequency and harmonic-target present (HTP) by entrainment frequency, for each participant.

\section{Source analysis}

A source reconstruction analysis was performed using a linearly constrained minimum variance (LCMV) beamformer (Van Veen, Van Drongelen, Yuchtman, \& Suzuki, 1997). In the absence of a T1 MRI for the participants, a $1 \mathrm{~mm}$ resolution template MRI was used to create the head model and 3D source model. The template MRI was co-registered to the MEG coordinates using the three fiducial points (i.e., nasion, left preauricular, and right preauricular point). The registered images were normalised to the MNI template using a nonlinear registration algorithm (Ashburner, 2007) 
bioRxiv preprint doi: https://doi.org/10.1101/2021.06.03.446932; this version posted June 3, 2021. The copyright holder for this preprint (which was not certified by peer review) is the author/funder, who has granted bioRxiv a license to display the preprint in perpetuity. It is made available under aCC-BY-NC-ND 4.0 International license.

and then used to define a homogeneous grid of $2 \mathrm{~mm}$ resolution. A single shell volume conduction model was created based on the segmentation of the head tissues. Lead fields were defined using the single shell head model to fit the head shape of each subject in the vicinity of each sensor. Spatial filter coefficients were estimated for each participant using the computed lead field and an average of the covariance matrix for all the epochs (both harmonic and inharmonic). Thereafter, this filter was used to compute the sources for each harmonic and inharmonic condition separately. This method results in independent scaling factors for all three spatial dimensions, thus enabling source localization with an accuracy close to that achieved with individual MR-based models. The source activity elicited by harmonic and inharmonic targets, in the time windows corresponding with the ERAN and RATN responses, were averaged over trials within each condition and the Monte Carlo Method was used to calculate the significance probability of variability using the dependent samples t-statistic. The following three analyses were performed in this way, on the source data in both the ERAN and the RATN time windows.

1. To examine inharmonic-harmonic event-related field (ERF) differences overall: Analysis of variance was performed between the source activations elicited by the inharmonic compared to the harmonic, at each entrainment frequency for the combined sample.

2. To examine inharmonic-harmonic ERF differences within each group separately: Analysis of variance was performed between the source activations elicited by the inharmonic compared to the harmonic targets for each entrainment frequency in each group separately.

3. To examine inharmonic-harmonic ERF differences between musicians and non-musicians: Analysis of variance was performed between the inharmonic-harmonic source activity differences, at each entrainment frequency, dependent on music group.

The design matrix for each analysis was for a within-subject manipulation. In order to have equal units of observation for the musicians versus non-musicians matrix (analysis number three), two musicians (participants 3 and 9) were randomly selected, in Matlab, to be excluded from the musician sample.

The source analysis is focused on inharmonic-harmonic differences for each entrainment frequency, dependent on music group, i.e., within-group effects investigating inharmonic-harmonic source activity differences for each group, and between group effects examining group differences in the ERF difference activity. Furthermore, all analyses were performed over the time windows associated with both the early ERAN response ( $200 \mathrm{~ms}$ ) and the later RATN ( $350 \mathrm{~ms})$ response. The methodology is designed to assess functional (strength of a response) and structural (location of a response) differences in the source activations in response to an inharmonic stimulus that is dependent on music training. The results of analyses conducted on data within the ERAN time window $(t=[175-225 \mathrm{~ms}])$ did not reach significance at an alpha level of 05 .

\section{Phase-amplitude coupling analysis}

For the PAC analysis the sources were computed for both harmonic and inharmonic trials combined, and across a time window of -1000 to $500 \mathrm{~ms}$. This source data was parcellated and used to generate virtual sensors. General Linear Models (GLMs) were estimated for centre frequencies between 3 and $12 \mathrm{~Hz}$, in steps of $1 \mathrm{~Hz}$, for the phase-frequency component and between 28 and $42 \mathrm{~Hz}$ with $1 \mathrm{~Hz}$ steps for the amplitude-frequency component, with a frequency resolution of $.5 \mathrm{~Hz}$. All 

made available under aCC-BY-NC-ND 4.0 International license.

epochs were concatenated to estimate the overall cross-frequency coupling, while the single epochs were entered individually into a separate GLM to test for significance at two alpha levels: .01, and .05. PAC correlation coefficients ( $\left.r_{\text {pac }}\right)$ were computed for participants in each (entrainment) condition (van Wijk, Jha, Penny, \& Litvak, 2015). Group averaged comodulograms were generated, both by averaging across the individual $r_{\text {pac }}$ images, and by averaging across the individual sig $g_{p a c}$ images. A series of paired $t$-tests were performed on the $r_{\text {pac }}$ images to examine statistical differences between conditions within each group (musicians and non-musicians) (for details see, van Wijk et al., 2016)

\section{Results}

\section{Reaction Time results}

Examination of the raw RT data using the Statistical Package for Social Sciences (IBM SPSS statistics 23.0) revealed a non-normal distribution with a positive skew for data in the $35 \mathrm{~Hz}$ condition $(W(20)=.889, p=.026$, the absolute skewness value for the data in this condition was .467). Subsequent analyses were conducted on the exponents of the means of log-transformed RT distributions, calculated in MATLAB using an in-house script (for supporting ideas see Box, \& Cox, 1982; Box \& Cox, 1964). A mixed repeated-measures analysis of variance (ANOVA) was applied to these data to evaluate the effect of entrainment frequency $(31 \mathrm{~Hz}, 33 \mathrm{~Hz}, 35 \mathrm{~Hz}, 37 \mathrm{~Hz}$, and $39 \mathrm{~Hz})$, and harmonic relation (harmonic and inharmonic targets) on RT responses, as a function of music experience (group being the between factor; musicians and non-musicians). Levene's test for equality of variance was applied to the analysis, as was Greenhouse-Geisser estimates of sphericity, and degrees of freedom were corrected when a violation to an assumption was indicated. Bonferroni correction was applied to all pairwise comparisons.

Significant main effects were found for target, and entrainment frequency; $F_{(1,19)}=6.13 p=$ $.023, \eta_{p}^{2}=.24, F_{(4,76)}=2.79, p=.032, \eta_{p}^{2}=.13$ respectively. The effect of group was not found to be significant $\left(F_{(1,19)}=.004, p=.95\right)$. The main effect for target was due to slower responses to harmonic compared to inharmonic targets $(M D=15.32, S E=6.19, p=.023)$. The main effect for entrainment frequency was due to faster RTs to targets with an entrainment frequency of $35 \mathrm{~Hz}$ compared to 31 $\mathrm{Hz}(M D=11.9, S E=3.25, p=.016)$. While the interaction between target and entrainment frequency was not significant $(p=.38)$, a pairwise comparison revealed significant RT differences between targets following $33 \mathrm{~Hz}, 37 \mathrm{~Hz}$, and $39 \mathrm{~Hz}$ entrainment $(M D=18.31, S E=6.68, p=.013, M D=15.58, S E=7.14$, $p=.042$, and $M D=19.08, S E=7.59, p=.021$, respectively). While the three-way interaction between group, target and entrainment frequency did not achieve significance $(p=.57)$, a pairwise comparison found the target by entrainment frequency effect (found for $33 \mathrm{~Hz}, 37 \mathrm{~Hz}$, and $39 \mathrm{~Hz}$ entrainment conditions) held following $33 \mathrm{~Hz}$ and $39 \mathrm{~Hz}$ entrainment - for non-musicians only $(M D=21.22, S E=$ 9.66, $p=.041$, and $M D=25.14, S E=10.99, p=.034$, respectively). 


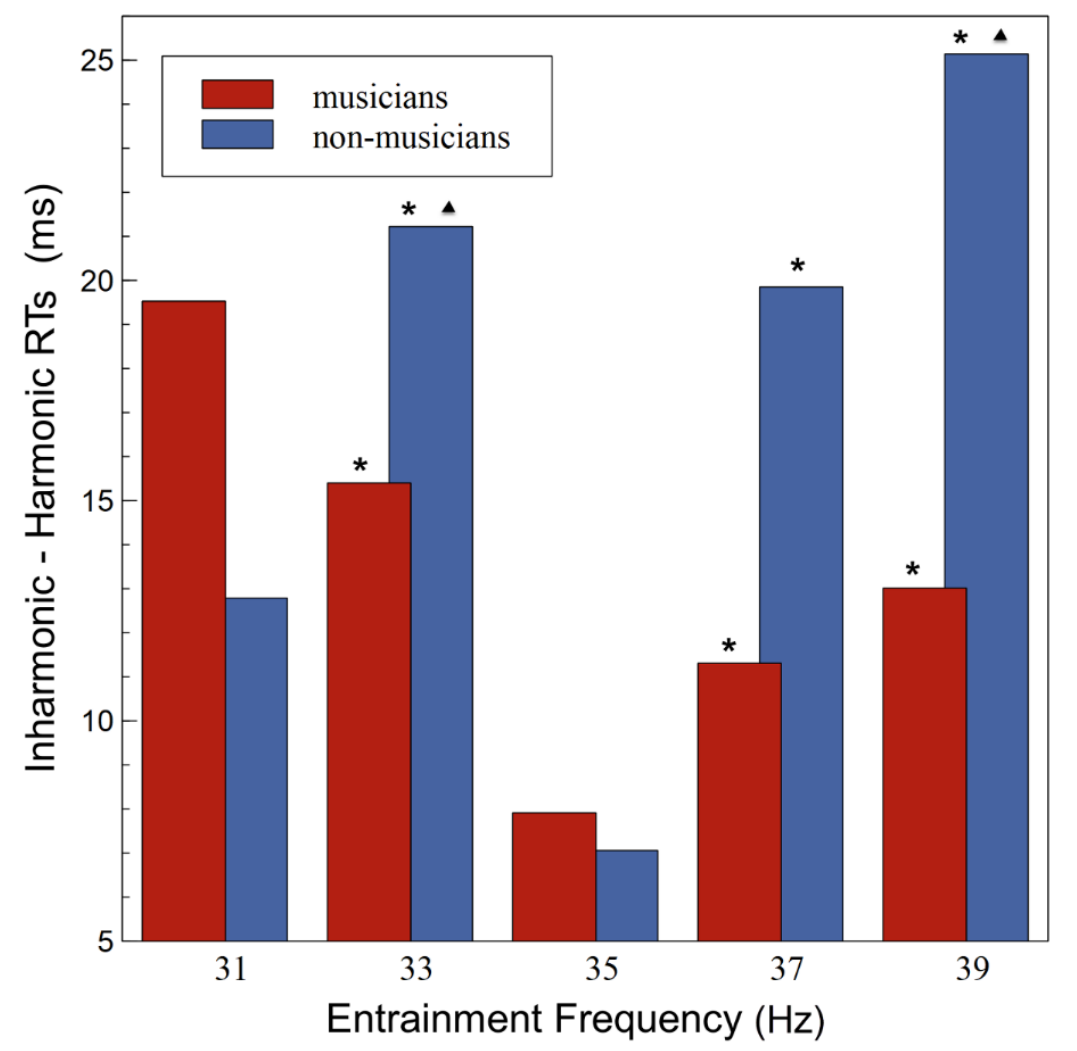

Figure 2. Differences in average reaction times (RTs) between harmonic and inharmonic responses, for each entrainment condition and group. Averaged harmonic RT responses subtracted from averaged inharmonic RT responses for musicians (red bar) and non-musicians (blue bar) for entrainment frequency condition ( $x$-axis). Pairwise comparison found faster responses to inharmonics following $33 \mathrm{~Hz}, 37 \mathrm{~Hz}$, and $39 \mathrm{~Hz}$ entrainment $\left({ }^{*}\right)$, while pairwise comparison of all three factors (group, target and entrainment frequency) revealed the RT difference remained significant for non-musicians only following $33 \mathrm{~Hz}$ and $39 \mathrm{~Hz}$ entrainment (triangles).

As anticipated the results revealed a $33 \mathrm{~Hz}$ inharmonic pop-out in the non-musician group data, consistent with that reported by Aksentijevic et al., (2011, 2014). A second pop-out was also found at $39 \mathrm{~Hz}$ for non-musicians. Following $35 \mathrm{~Hz}$ entrainment the difference in responses for both groups to both targets was very small, with a main effect found which indicated responses for conditions with an entrainment frequency of $35 \mathrm{~Hz}$ were significantly faster compared to an entrainment frequency of $31 \mathrm{~Hz}$. Aksentijevic et al., (2014) found a main effect of entrainment frequency for $33 \mathrm{~Hz}$ and $35 \mathrm{~Hz}$ conditions, thought to reflect attentional mechanisms which rely on the temporal features of the sound, communicated by the envelope fluctuations of the entrainment (AM) frequency. Furthermore, the musicians' responses were not faster overall compared to nonmusicians, contrary to the responses of the musicians in the Aksentijevic et al., (2014) sample of jazz musicians. However, while jazz and classical musicians have been found to possess similar levels of tonal ability, jazz musicians demonstrate a greater sensitivity to auditory deviants - resulting in a larger auditory mismatch-negativity (MMN) response (Vuust, Brattico, Seppänen, Näätänen, \& Tervaniemi, 2012). It is considered this could result in greater accuracy and faster responses to the auditory stimuli used within the paradigm, although further investigation would be needed to clarify. 
bioRxiv preprint doi: https://doi org/10.1101/2021.06.03 446932; this version posted June 3, 2021. The copyright holder for this preprint (which was not certified by peer review) is the author/funder, who has granted bioRxiv a license to display the preprint in perpetuity. It is made available under aCC-BY-NC-ND 4.0 International license.

The main finding from the analysis of the RT data is that entrainment of $33 \mathrm{~Hz}, 37 \mathrm{~Hz}$, and 39 $\mathrm{Hz}$ resulted in responses to inharmonics that were significantly faster compared to harmonic responses. Furthermore, a group comparison showed that musicians' responses to harmonics and inharmonics did not differ significantly across all entrainment conditions, while non-musicians demonstrated faster responses to inharmonic than to harmonic target tones, following $33 \mathrm{~Hz}$ and 39 $\mathrm{Hz}$ entrainment.

\section{Source analysis}

Source locations from MEG activity, found to be significant during the RATN time window $(t=$ [325 - $375 \mathrm{~ms}]$ ), were inconsistent with the expected RATN location, i.e., right frontotemporal region as described by Patel et al. (1998). However, significant inharmonic-harmonic ERF differences were found within the RATN time window during entrainment conditions that were consistent with significant inharmonic-harmonic RT outcomes. To recap, analysis of the RT data revealed faster responses to the inharmonic targets following entrainment at $33 \mathrm{~Hz}, 37 \mathrm{~Hz}$, and $39 \mathrm{~Hz}$ entrainment frequencies. However, a multiple comparisons analysis of the factor-level effects determined a priming effect due to significantly faster responses to inharmonic compared to harmonic targets following $33 \mathrm{~Hz}$ and $39 \mathrm{~Hz}$ entrainment, for non-musicians only.

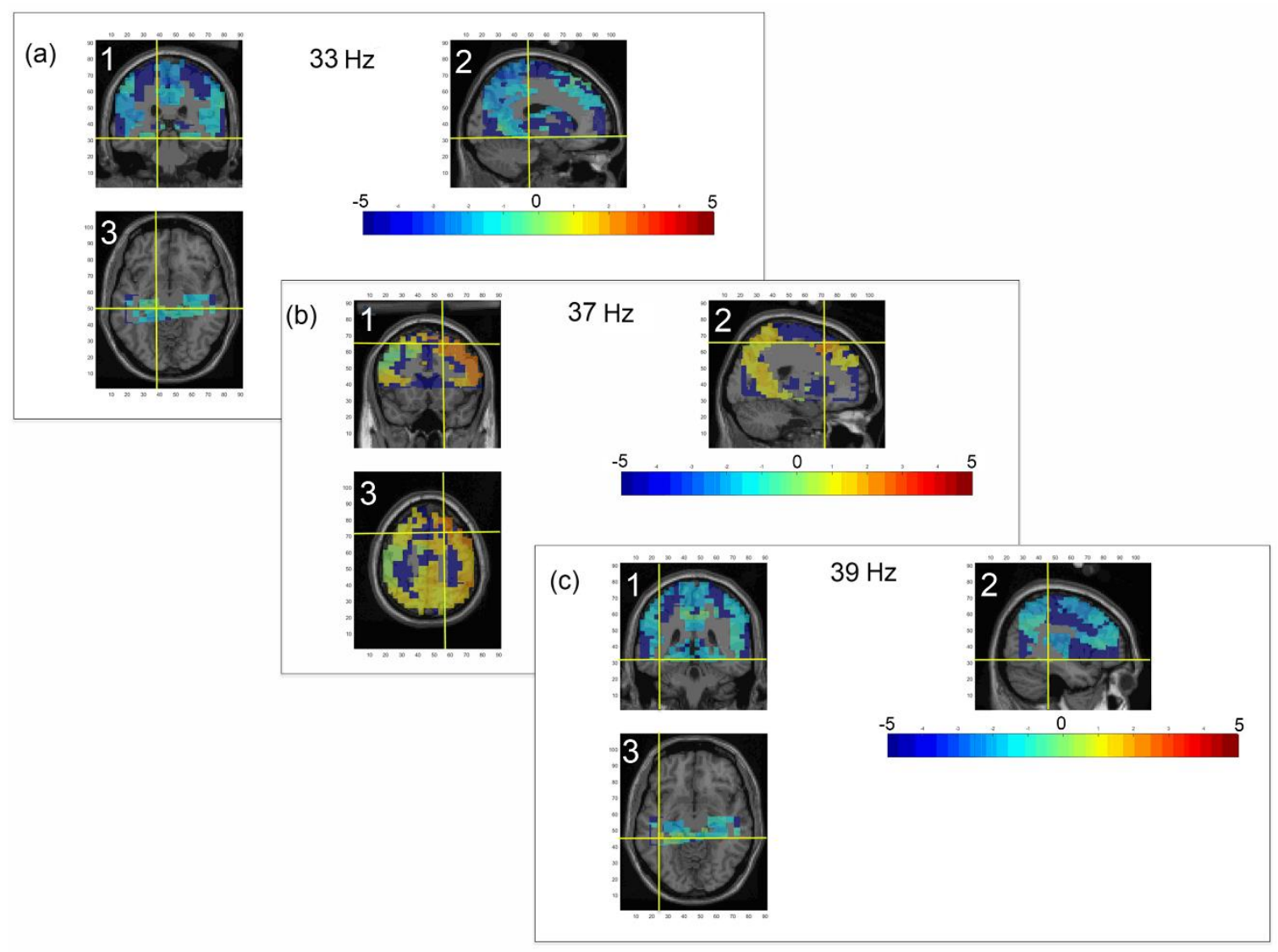

Figure 3. Mean images depicting the MEG source localisation of the difference between harmonic and inharmonic ERF activation, $350 \mathrm{~ms}$ post-stimulus onset (time window = [325 - $375 \mathrm{~ms}$ ]), for musicians and non-musicians combined, following entrainment frequencies of (a) $33 \mathrm{~Hz}$, (b) $37 \mathrm{~Hz}$, and (c) $39 \mathrm{~Hz}$. For each condition, the source location is presented in (1) coronal (2) sagittal and (3) 
bioRxiv preprint doi: https://doi org/10.1101/2021.06.03.446932; this version posted June 3, 2021. The copyright holder for this preprint (which was not certified by peer review) is the author/funder, who has granted bioRxiv a license to display the preprint in perpetuity. It is made available under aCC-BY-NC-ND 4.0 International license.

transverse views. Source activities identified: (a) left hippocampus and parahippocampal area (MNI coordinates [-16 -30 -12] mm), following $33 \mathrm{~Hz}$ entrainment; (b) right superior frontal cortex (MNI coordinates [ 201656$]$ mm), following $37 \mathrm{~Hz}$ entrainment; and (c) left inferior temporal lobe (MNI coordinates [- 42 - 38 - 12] mm), following $39 \mathrm{~Hz}$ entrainment. Values plotted are the cluster tstatistics within the range -5 to 5 (see colour bar), with significant clusters $(p<.05)$ marked by the crosshair.

(a)
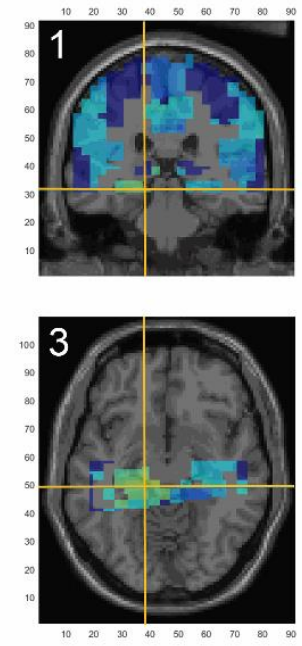

(b)
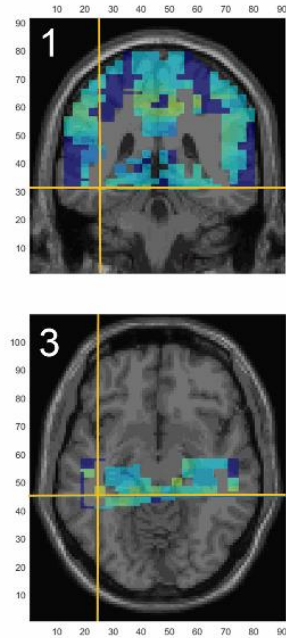

$33 \mathrm{~Hz}$

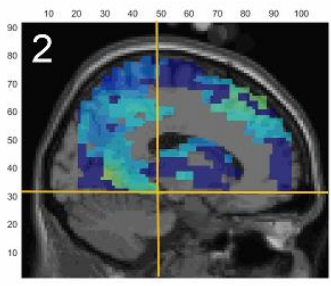

0
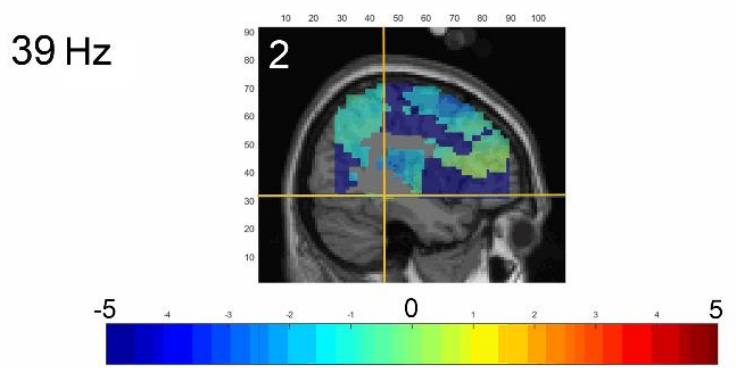

Figure 4. Mean images depicting the source localisation of the difference between harmonic and inharmonic ERF activation, 350 ms post-stimulus onset (time window = [325 - $375 \mathrm{~ms}]$ ), following entrainment frequencies of (a) $33 \mathrm{~Hz}$ and (b) $39 \mathrm{~Hz}$, for the non-musician group. For each condition, the source location is presented in (1) coronal (2) sagittal and (3) transverse views. As for the combined data under the same entrainment conditions, $(a, 33 \mathrm{~Hz})$ is located in the left hippocampus and parahippocampal area (MNI coordinates [-16 -30 -12] $\mathrm{mm}$ ), and $(\mathrm{b}, 39 \mathrm{~Hz})$ in the left inferior temporal lobe (MNI coordinates [- 42 - 38 - 12] mm). Values plotted are the cluster $t$-statistics within the range -5 to 5 (see colour bar), with significant clusters $(p<.05)$ marked by the crosshair. 
Firstly, the analysis of variance between the ERF generated by the inharmonic compared to the harmonic, for the combined sample (musicians and non-musicians), found the strength of the response to be increased for the inharmonic following entrainment frequencies of $33 \mathrm{~Hz}, 37 \mathrm{~Hz}$ and $39 \mathrm{~Hz}\left(33 \mathrm{~Hz}\right.$, cluster statistic $=-3.8905 \times 10^{3}, p=.015 ; 37 \mathrm{~Hz}$, cluster statistic $=1.3703 \times 10^{3}, p=.0043$; $39 \mathrm{~Hz}$, cluster statistic $=-973.086, p=.044)$. This finding was replicated in the second analysis of variance among the non-musician cohort only, following entrainment frequencies of $33 \mathrm{~Hz}$ and $39 \mathrm{~Hz}$ ( $33 \mathrm{~Hz}$, cluster statistic $=-2.749 \times 10^{3}, p=.022 ; 39 \mathrm{~Hz}$, cluster statistic $\left.=-878.7248 \times 10^{3}, p=.037\right)$.

When a threshold alpha-value of 0.05 was adopted for the dependent samples t-statistic, to initially threshold the data for the cluster analysis, a group difference did not reach significance. However, inharmonic-harmonic ERF source differences that have similar activation strengths and locations for both groups will go undetected, even though the ERF difference may be significant for both groups, simply as they will not be significantly different for one group compared to the other. Lowering the initial thresholding alpha value to 0.01 to restrict the critical values entered in the cluster-based permutation routines, allows for more subtle group differences to be detected (for details see Gaab \& Schlaug, 2003). Taking this approach, significant group differences were found for both groups - in separate locations, following $33 \mathrm{~Hz}$ entrainment. A significant variance in inharmonicharmonic ERF source activity was found for musicians compared to non-musicians, in the middle frontal gyrus (cluster statistic $=221.018, p=.033$, see Figure 5), and for non-musicians compared to musicians in the left parahippocampal and left fusiform gyri (cluster statistic $=-221.018, p=.05$, see Figure 6).
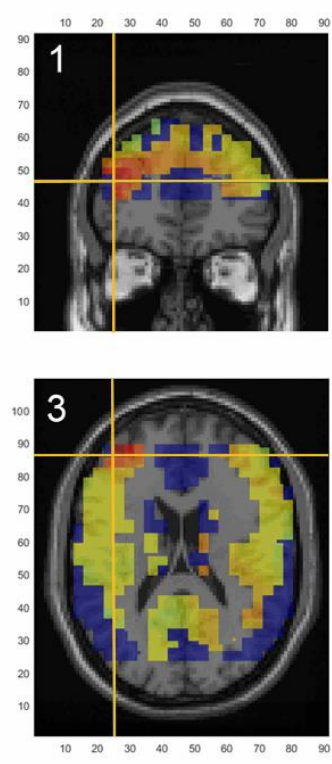

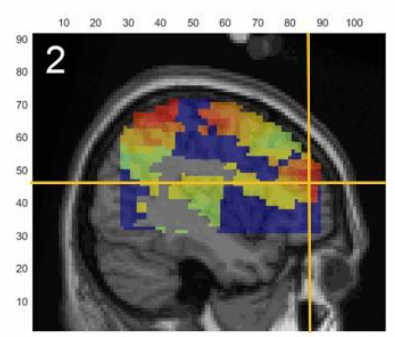

0 5



Figure 5. Mean image depicting the source localisation for the inharmonic-harmonic difference ERF activation showing a significant increase in strength for the musician group following $\mathbf{3 3} \mathbf{~ H z}$ entrainment, when an alpha threshold of $\mathbf{0 . 0 1}$ was applied. Location: left middle frontal gyrus (MNI coordinates [- 4244 18] mm), $350 \mathrm{~ms}$ post stimulus onset, displayed in (1) coronal (2) sagittal and (3) transverse views. Values plotted are the cluster t-statistics within the range -5 to 5 (see colour bar), with significant clusters $(p<.01)$ marked by the crosshair. 

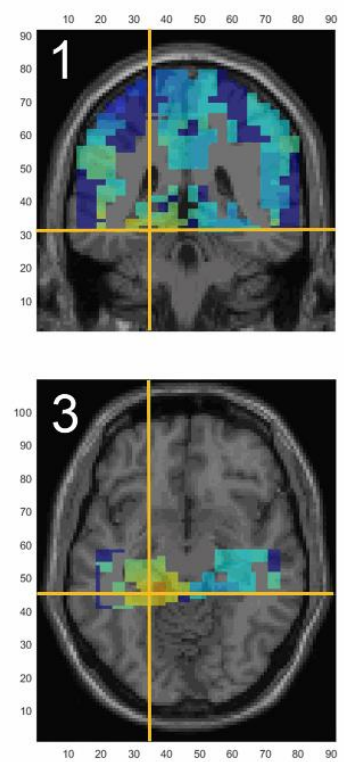

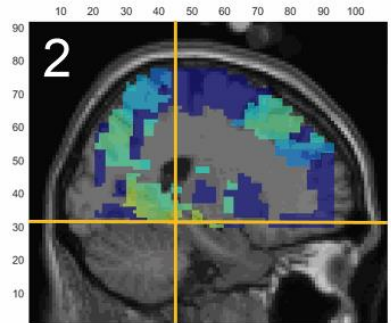

0

$-5$

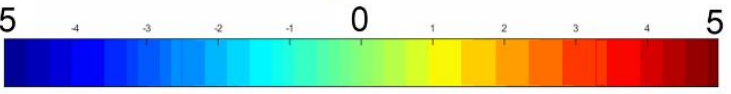

Figure 6. Mean image depicting the source localisation for the inharmonic-harmonic difference ERF activation showing a significant increase in strength for the non-musician group following $\mathbf{3 3}$ $\mathrm{Hz}$ entrainment. An alpha threshold of 0.01 used. Location: left parahippocampal and left fusiform gyri (MNI coordinates [- 22 -38 -12] mm), 350 ms post stimulus onset, displayed in (1) coronal (2) sagittal and (3) transverse views. Values plotted are the cluster t-statistics within the range -5 to 5 (see colour bar), with significant clusters $(p<.01)$ marked by the crosshair.

Interestingly, in support of the RT findings, which found the responses to the inharmonic were made significantly more quickly than those to the harmonic, for non-musicians, following $33 \mathrm{~Hz}$ and $39 \mathrm{~Hz}$ entrainment - the results of the source level analysis indicate that a response to a deviant stimulus is stronger for non-musicians compared to musicians, when an aGBR of $33 \mathrm{~Hz}$ and $39 \mathrm{~Hz}$ is elicited via stimulus entrainment. However, following stimulus entrainment at $33 \mathrm{~Hz}$, RATN source locations differ for musicians and non-musicians. Interestingly, the effects are only evident during the later RATN time window. It is possible that the entrainment stimuli, while containing tonal components, did not elicit an ERAN response which is passively evoked when syntactical anomalies occur in music, or that stimulus entrainment may disrupt the early ERAN response for both groups. However, the suggestion is that the RATN response elicited by irregular tones that are unknown or unpredictable, was improved under certain stimulus entrainment conditions. Considering this convergence of behavioural RT evidence with source activations, a frequency power analysis was conducted to examine the neural evidence for an aGBR evoked through stimulus entrainment using this auditory paradigm, to establish whether the entrainment of an aGBR differed between musicians and non-musicians.

\section{Frequency power analysis}

The stimuli in the experiments conducted by Galambos and colleagues (Galambos et al., 1981; Galambos, 1992) used single pure tones, i.e., comprising only one CF, whereas the current paradigm used two CF's per pip-train. Furthermore, research using the current paradigm relies on the persistence effects of an evoked aGBR across a range of gamma frequencies. A pure tone burst of 500 
ms in duration has been demonstrated to persist within 100 to 120 ms post stimulus onset (Christo Pantev \& Elbert, 1994). Furthermore, the current pip-train stimuli have produced persistence effects at up to $400 \mathrm{~ms}$ post-stimulus offset (Aksentijevic et al., 2013). Hence, a frequency power analysis was next conducted to explore the neural evidence, at sensor level over temporal cortex, for successful entrainment to the pip-train stimuli that persists during the $100 \mathrm{~ms}$ inter-stimulus interval between the prime and the target, dependent on the entrainment frequency, and music ability.

The time frequency data for each entrainment frequency condition, and each group, were epoched for the entrainment period $(-1000 \mathrm{~ms}$ to $0 \mathrm{~ms})$. A grand average was calculated. These data were used to perform a multi-taper method fast Fourier transform (mtmfft) using a discrete prolate spheroidal sequences (dpss) multi-taper, in Fieldtrip (Oostenveld et al., 2011), to calculate the average frequency content, within the range 28 to $45 \mathrm{~Hz}$, during the $100 \mathrm{~ms}$ ISI between the entrainer and target presentation, as measured at all channels covering both temporal lobes, at each entrainment frequency, and for each group. The results were then plotted for each group (see Figure 7). 
bioRxiv preprint doi: https://doi.org/10.1101/2021.06.03 446932; this version posted June 3, 2021. The copyright holder for this preprint (which was not certified by peer review) is the author/funder, who has granted bioRxiv a license to display the preprint in perpetuity. It is made available under aCC-BY-NC-ND 4.0 International license.

(a)

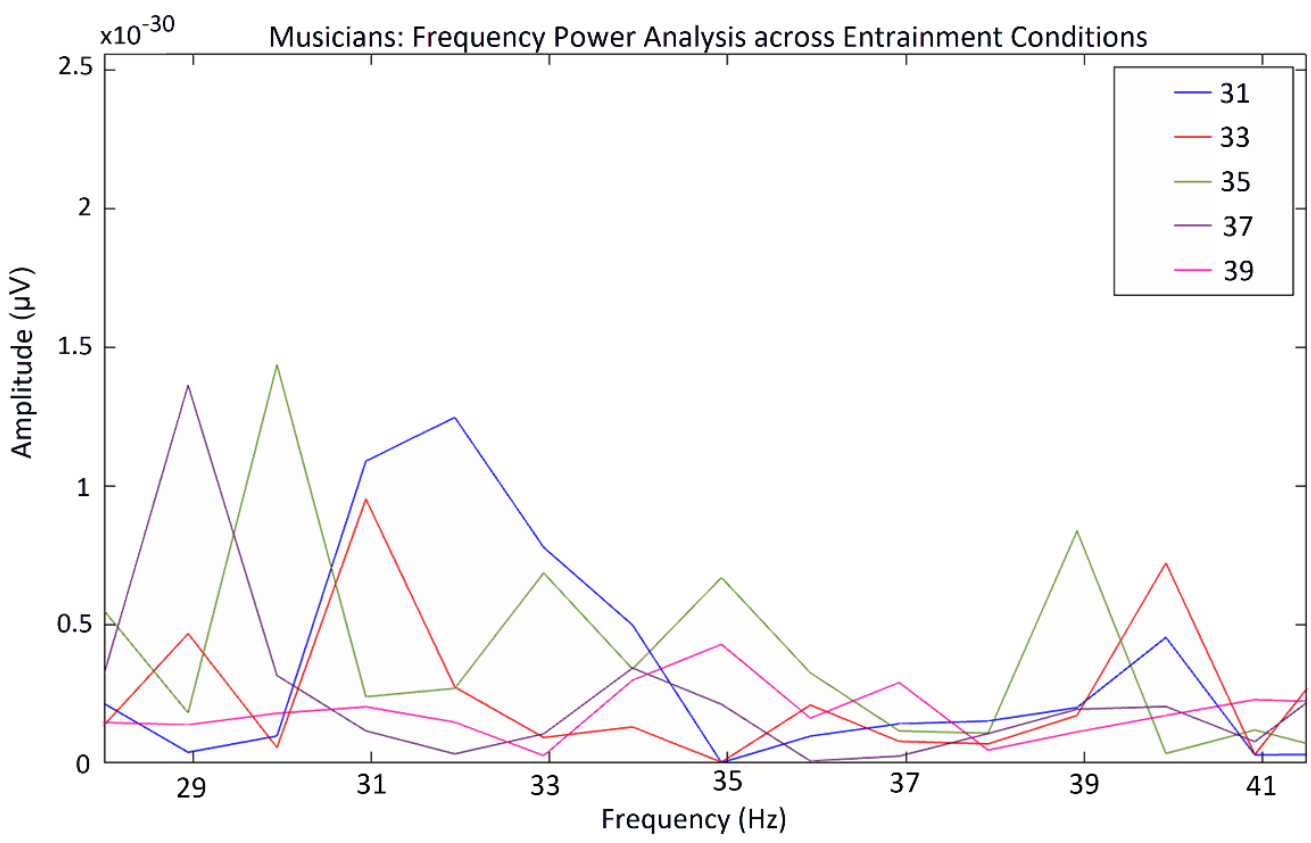

(b)

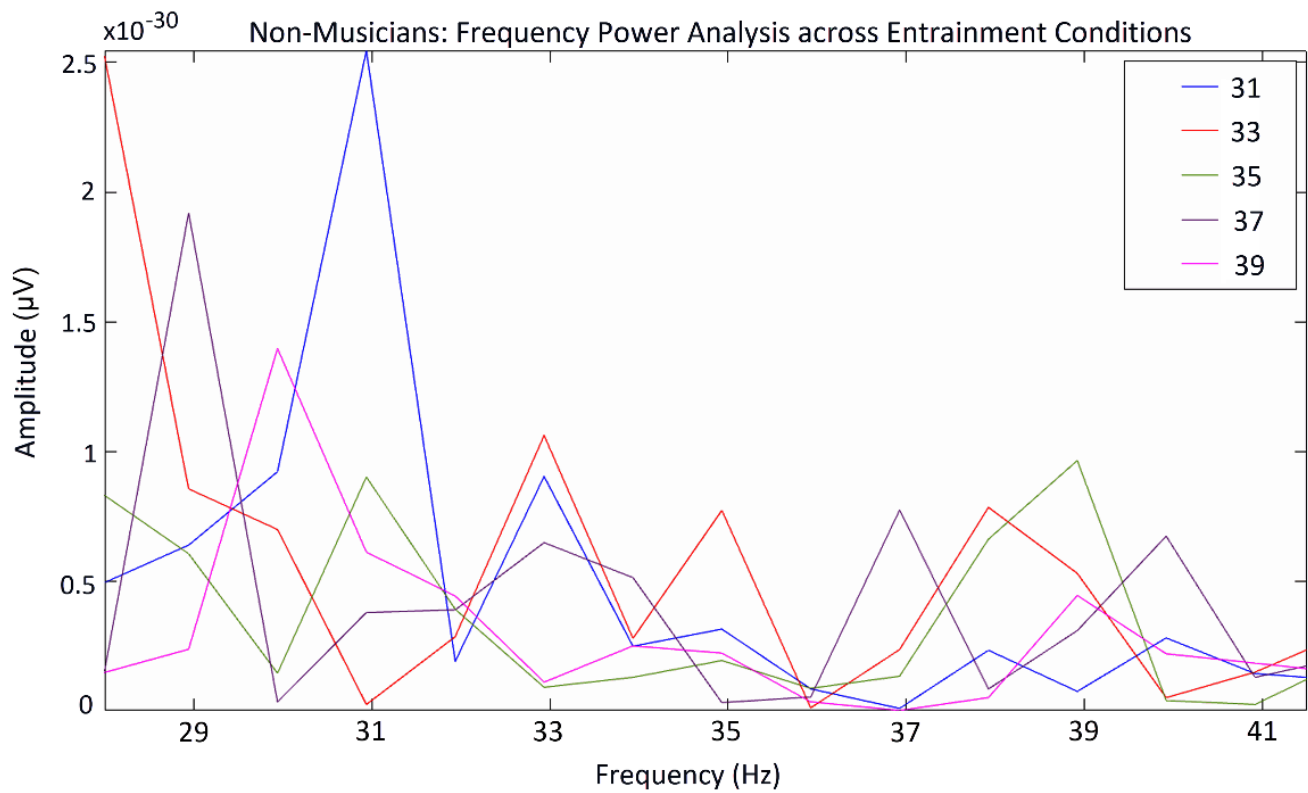

Figure 7. Frequency power spectral analysis during the $\mathbf{1 0 0} \mathrm{ms}$ interval between entrainer offset and target onset. (a) Musician; (b) non-musician. Bandpass filtered between 28 and $42 \mathrm{~Hz}$. Legend: Each entrainment condition. Frequency $(\mathrm{Hz})$ is presented on the $\mathrm{x}$-axis and amplitude $(\mu \mathrm{V})$ is presented on the $y$-axis.

Non-musicians: The amplitude of gamma frequencies between $28 \mathrm{~Hz}$ and $31 \mathrm{~Hz}$ was much higher for non-musicians. However, and as anticipated, under the $31 \mathrm{~Hz}, 33 \mathrm{~Hz}$, and $37 \mathrm{~Hz}$ entrainment conditions a peak in the corresponding frequency was evident. Furthermore, within the range of 31 $\mathrm{Hz}$ to $39 \mathrm{~Hz}$, the highest peak during the $31 \mathrm{~Hz}, 33 \mathrm{~Hz}$, and $37 \mathrm{~Hz}$ entrainment conditions occurs at the corresponding neural oscillatory frequency. This pattern was not evident from the data within the 35 $\mathrm{Hz}$ and $39 \mathrm{~Hz}$ entrainment conditions, where two peaks occur for frequencies separated by 8-9 $\mathrm{Hz}$. To elucidate, following $35 \mathrm{~Hz}$ there was a peak in the amplitude of $31 \mathrm{~Hz}$ and $39 \mathrm{~Hz}$, and following $39 \mathrm{~Hz}$ 
bioRxiv preprint doi: https://doi.org/10.1101/2021.06.03.446932; this version posted June 3, 2021. The copyright holder for this preprint (which was not certified by peer review) is the author/funder, who has granted bioRxiv a license to display the preprint in perpetuity. It is made available under aCC-BY-NC-ND 4.0 International license.

entrainment there was a peak in the amplitude of $30 \mathrm{~Hz}$ and $39 \mathrm{~Hz}$, and in both cases all other frequencies exhibit low amplitudes. Interestingly, $36 \mathrm{~Hz}$ was almost completely absent from all entrainment conditions. Musicians: By contrast the power spectrum obtained from the musician group suggested the amplitude of gamma frequencies within the range $31 \mathrm{~Hz}$ to $39 \mathrm{~Hz}$ was unrelated to entrainment frequency, except perhaps at $31 \mathrm{~Hz}$. However, while a peak in $31 \mathrm{~Hz}$ was evident within the corresponding entrainment frequency condition, the trend in the data for this condition, and similarly for an entrainment frequency of $33 \mathrm{~Hz}$ suggested a more exaggerated two-peak pattern, with a spike in the amplitude of $31-32 \mathrm{~Hz}$ and $40 \mathrm{~Hz}$, and a complete attenuation of $35 \mathrm{~Hz}$, hence a peakto-peak separation of $9 \mathrm{~Hz}$.

Thus, the evoked aGBRs demonstrated signs of a $9 \mathrm{~Hz}$ (alpha) modulation, which was more pronounced for musicians. Furthermore, for non-musicians, following each entrainment the greatest peak in amplitude occurred for the corresponding frequency, suggesting the aGBR was successfully evoked. Given the 8-9 Hz separation between the frequencies that exhibit higher amplitudes, under some entrainment conditions, in the $100 \mathrm{~ms}$ period between the termination of the entrainment stimulus and the onset of the target, a phase-amplitude coupling analysis was conducted to explore underlying interactions which might give rise to this effect.

\section{Phase-amplitude coupling (PAC) results}

In addition to the effect of priming on RT responses to a deviant stimulus, found for nonmusicians, findings from previous work strongly suggests that enhanced (i.e., significantly faster) RT responses to deviant tones are a consequence of an interaction between the aGBRs, evoked by the entrainment stimulus, and endogenous brain rhythms in the theta range - approximately $2 \mathrm{~Hz}$ below the suggested influence of alpha on the evoked aGBRs, inferred from the spectrograms in Figure 7 (Elliott, 2014; Elliott \& du Bois, 2017). The current research provided the opportunity to investigate the support for such an interaction through an examination of gamma-theta phase-amplitude coupling (PAC), whereby the instantaneous phase of endogenous theta modulates the instantaneous amplitude of gamma oscillations. PAC coupling has been linked to working memory processing and information exchange by providing windows of coherence between participating neural networks (Penny, Duzel, Miller, \& Ojemann, 2008; Scheffer-Teixeira et al., 2012; Schomburg et al., 2014). Figure 8 to Figure 10, and Supporting Figure 1 to Supporting Figure 5 in supporting material, illustrate the modulation of the amplitude of gamma frequencies covering the range of entrainment frequencies used in this paradigm by the phase of high delta, theta, and alpha during each entrainment condition, for both groups. The averaged PAC values for each group, are presented in the top row of these figures, marked (a). The darker the colour of the voxels in these colour comodulograms, the higher the PAC value for that frequency combination, as can be seen from the indictor at the right side of the comodulograms. When interpreting the gray scale comodulograms in the second row, marked (b), the grey and white voxels represent the proportion, or percentage, of the sample for whom this frequency combination had a PAC value that was significant at alpha levels of 0.05 and 0.01 , respectively, as can be seen by the indictor at the right side of the comodulograms, i.e., black voxels were not significant and the number at the top of the column (indicator) represents the proportion of people for whom the PAC was significant. By comparing the peaks in the spectral density graphs, marked (c) for the slow waves, and (d) for the gamma frequencies, with these comodulograms ((a) and (b)), consistencies between high PAC values that were also found to be significant, and the proportion of that group (musician or non-musician) for whom they were significant, can be examined. 
bioRxiv preprint doi: https://doi.org/10.1101/2021.06.03.446932; this version posted June 3, 2021. The copyright holder for this preprint (which was not certified by peer review) is the author/funder, who has granted bioRxiv a license to display the preprint in perpetuity. It is made available under aCC-BY-NC-ND 4.0 International license.

A within-subject analysis of changes in PAC across entrainment conditions found a significant difference for non-musicians only, between the $33 \mathrm{~Hz}$ and $37 \mathrm{~Hz}$ entrainment conditions (see Figure 8 and Figure 9). It is speculated that this is driven by a $6-7 \mathrm{~Hz}$ theta modulation that is significant for $25-30 \%$ of the non-musician group following entrainment of a $33 \mathrm{~Hz} \mathrm{GBR}$ compared to entrainment of a $37 \mathrm{~Hz} \mathrm{GBR}$. Interestingly, $36 \mathrm{~Hz}$ appears to be attenuated, i.e., not present, across entrainment conditions in the spectrogram for non-musicians (see Figure 7).

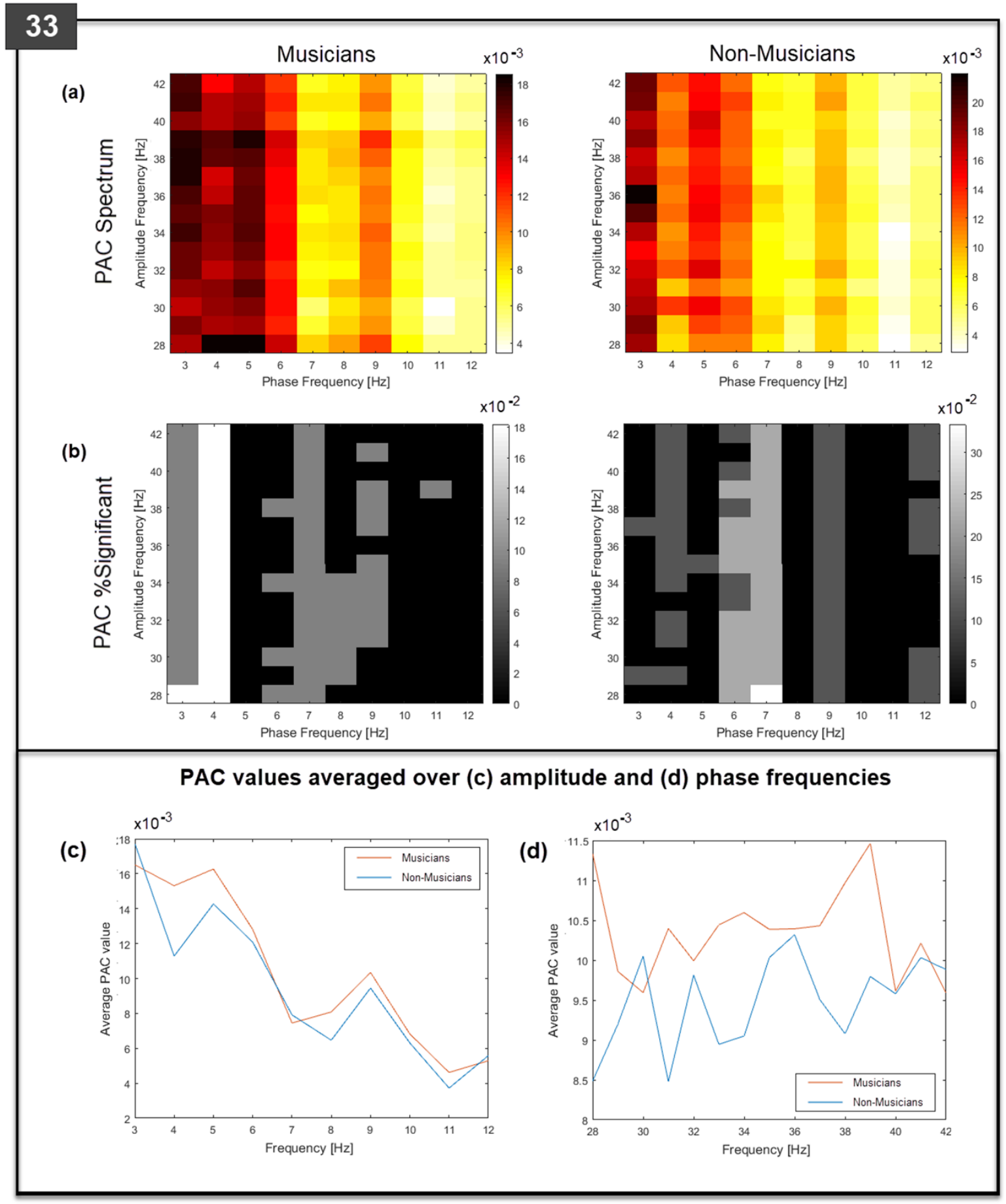

Figure 8. Grand-averaged PAC spectral densities for musicians and non-musicians during the $33 \mathrm{~Hz}$ entrainment condition (top left corner). (a) Grand-averaged PAC values for each gamma and slow wave frequency combination in the spectrum. (b) Percentage cases with significant PAC (white; $p<$ 
bioRxiv preprint doi: https://doi.org/10.1101/2021.06.03.446932; this version posted June 3, 2021. The copyright holder for this preprint (which was not certified by peer review) is the author/funder, who has granted bioRxiv a license to display the preprint in perpetuity. It is made available under aCC-BY-NC-ND 4.0 International license.

0.01 , and grey; $p<0.05$ ) for each gamma and slow wave frequency combination in the spectrum. (c) and (d) Spectral densities for 'musicians' (red legend) and 'non-musicians' (blue legend).

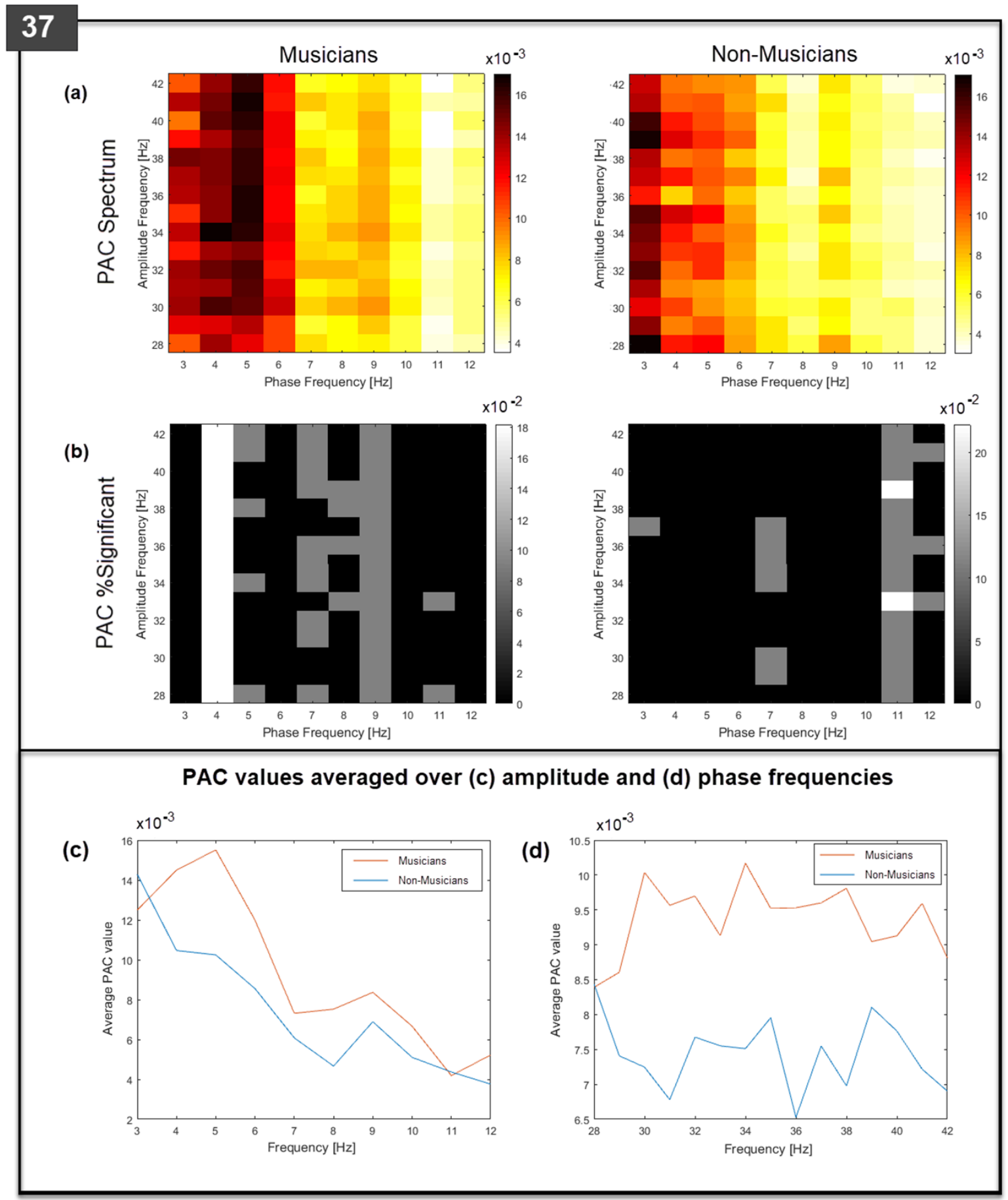

Figure 9. Grand-averaged PAC spectral densities for musicians and non-musicians during the $37 \mathrm{~Hz}$ entrainment condition (top left corner). (a) Grand-averaged PAC values for each gamma and slow wave frequency combination in the spectrum. (b) Percentage cases with significant PAC (white; $p<$ 0.01 , and grey; $p<0.05$ ) for each gamma and slow wave frequency combination in the spectrum. (c) and (d) Spectral densities for 'musicians' (red legend) and 'non-musicians' (blue legend). 
bioRxiv preprint doi: https://doi.org/10.1101/2021.06.03.446932; this version posted June 3, 2021. The copyright holder for this preprint (which was not certified by peer review) is the author/funder, who has granted bioRxiv a license to display the preprint in perpetuity. It is made available under aCC-BY-NC-ND 4.0 International license.

Notably, the proportion of musicians contributing to a significant PAC value does not exceed $18 \%$ of the overall group - yet remains consistent across conditions and seems to be generally representative of high pac $\left(r_{\mathrm{pac}}\right)$ values (see the indicator on the right of the significance comodulograms for musicians, in Supporting Figure 1 to Supporting Figure 5 in supporting material). Moreover, the peaks in the spectral density graphs are largely representative of the phase modulation frequencies that produce a modulation effect, i.e., have higher PAC values, across the spectrum of amplitude frequencies, for approximately $18 \%$ of the sample, in each condition. The most prominent frequency modulations occur in phase with $4 \mathrm{~Hz}$ theta, and 8-9 $\mathrm{Hz}$ alpha rhythms. Interestingly, there is a complete absence of a $4 \mathrm{~Hz}$ modulation effect under the $39 \mathrm{~Hz}$ entrainment condition, coupled with lower averaged delta range PAC values across the gamma amplitude frequencies, evidenced for both groups. 
bioRxiv preprint doi: https://doi.org/10.1101/2021.06.03.446932; this version posted June 3, 2021. The copyright holder for this preprint (which was not certified by peer review) is the author/funder, who has granted bioRxiv a license to display the preprint in perpetuity. It is made available under aCC-BY-NC-ND 4.0 International license.

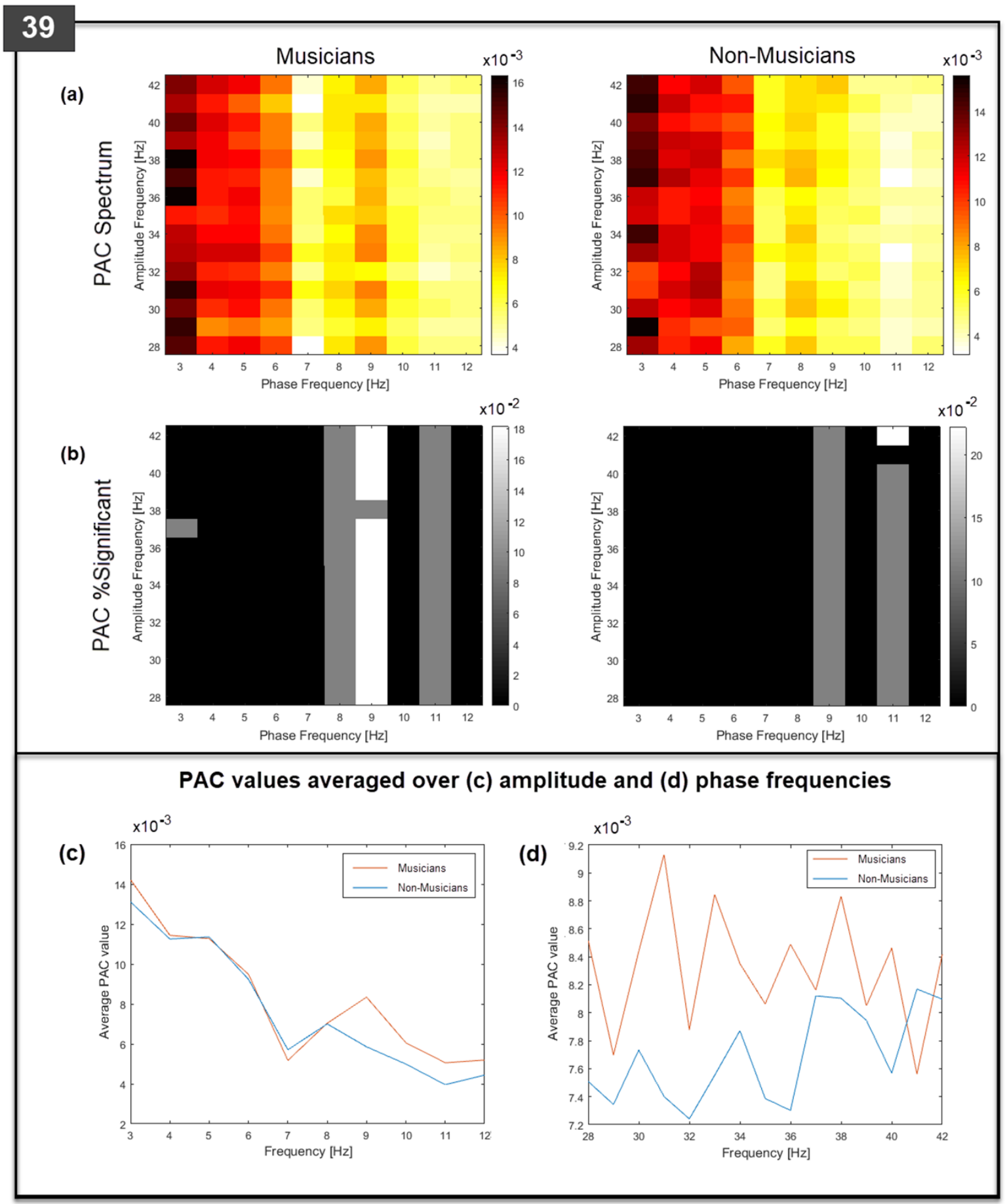

Figure 10. Grand-averaged PAC spectral densities for musicians and non-musicians during the 39 Hz entrainment condition (top left corner). (a) Grand-averaged PAC values for each gamma and slow wave frequency combination in the spectrum. (b) Percentage cases with significant PAC (white; $p<0.01$, and grey; $p<0.05$ ) for each gamma and slow wave frequency combination in the spectrum. (c) and (d) Spectral densities for 'musicians' (red legend) and 'non-musicians' (blue legend).

In contrast, more variation occurs between conditions for the proportion of non-musicians for whom the same frequency combinations resulted in significant PAC values - as can be seen from the indicator to the right of the significance comodulograms, for each entrainment condition, for non- 
bioRxiv preprint doi: https://doi.org/10.1101/2021.06.03.446932; this version posted June 3, 2021. The copyright holder for this preprint (which was not certified by peer review) is the author/funder, who has granted bioRxiv a license to display the preprint in perpetuity. It is made available under aCC-BY-NC-ND 4.0 International license.

musicians; $31 \mathrm{~Hz}$ (10\%), $33 \mathrm{~Hz}$ (30\%), $35 \mathrm{~Hz}(20 \%), 37 \mathrm{~Hz}$ (20\%), and $39 \mathrm{~Hz}$ (20\%) (see Supporting Figure 1 to Supporting Figure 5 in supporting material). Thus, the 4,9 and $12 \mathrm{~Hz}$ modulation during the $31 \mathrm{~Hz}$ entrainment condition, which was observed for all amplitude frequencies, was only significant for $10 \%$ of the group, while the $7 \mathrm{~Hz}$ modulation during the $33 \mathrm{~Hz}$ entrainment condition was significant across the full range of gamma for $30 \%+$ of the non-musicians, and a $9 \mathrm{~Hz}$ modulation across the full gamma range for $15-20 \%$. While not extending across the full range of gamma, the $6 \mathrm{~Hz}$ modulation was also representative of $30 \%+$ of the group - and corresponding PAC values were slightly increased in strength compared to the 7 and $9 \mathrm{~Hz}$ interactions, as can be seen from the spectral density graph (c) in Figure 8. Interestingly, previous research using stimulus entrainment in both the visual and auditory domain has asserted that a facilitation of responses, notably the pop-out effect associated with $33 \mathrm{~Hz}$ entrainment, can be attributed to an interaction with a theta rhythm of approximately $6-7 \mathrm{~Hz}$ (Aksentijevic et al., 2011; Elliott, 2014; Elliott \& du Bois, 2017). The significant 6-7 Hz modulation observed in these data for a approximately one-third of the sample following $33 \mathrm{~Hz}$ entrainment, supports this assertion - and may reflect a greater influence of entrainment on non-musicians' tone discrimination. In turn, this observed influence suggests a greater reliance on the stimulus (bottomup) information, that is subserved by gamma-band frequencies, while the more general phase modulation of gamma amplitude by specific endogenous frequencies found for musicians may echo a top-down training induced response.

\section{Discussion}

The current research aimed to investigate functional differences in the neural mechanisms of auditory cognition that derive from music training. The purpose of using an auditory prime that simultaneously primes a harmonic expectancy (based on the carrier frequencies) and entrains a gamma-band response that is phase locked to the primed AM frequency, was to provide a means to examine these functional differences through the lens of the priming effect - and how or if this effect differs when the brain has been plastically altered through music training.

Previous research has shown differences in priming the auditory system with gamma-band entrainment frequencies that occur as a consequence of music training (Aksentijevic et al., 2011, 2013, 2014). An aGBR is presumed to be evoked by, and phase-locked to, the entrainer stimulus. External stimulus information is known to be carried by frequencies in the gamma-band range as the phase cycle of these frequencies is fast enough to feedforward prediction errors to update models that have been based on previous learning (Fries, 2015; Michalareas et al., 2016). Moreover, the harmonic relations embedded in the entrainer stimulus generates the listeners' expectancies regarding the next event - the harmonic target is an expected event (consonant), and the inharmonic is an unexpected, or deviant event (dissonant). Consistent with previous research, the results from the behavioural (RT) data revealed a $33 \mathrm{~Hz}$ entrainment frequency specific pop-out effect for non-musicians only. However, deviating from previous findings - a pop-out effect was also found following $39 \mathrm{~Hz}$ entrainment (see Figure 2). Furthermore, the musicians in the current sample did not exhibit faster RTs compared to non-musicians - possibly a reflection of differences in sensitivity to auditory outliers due to type of music training (current classical versus previous jazz, musicians). Importantly, consistent with the Aksentijevic sample, musicians' responses to inharmonic targets, while faster than responses to harmonic targets, did not differ significantly across all rates of entrainment (inharmonic-harmonic RTs, $p>0.05$ ) (Aksentijevic et al., 2014). 
bioRxiv preprint doi: https://doi.org/10.1101/2021.06.03.446932; this version posted June 3, 2021. The copyright holder for this preprint (which was not certified by peer review) is the author/funder, who has granted bioRxiv a license to display the preprint in perpetuity. It is made available under aCC-BY-NC-ND 4.0 International license.

In general, differences in the effect of priming using stimulus entrainment as a function of music training were demonstrated in relation to the RATN response - an evoked response to irregular tone structures within an unpredictable sequence (Headley \& Weinberger, 2011). Source analyses during this later (RATN) time window (325-375 ms), found the ERF response to the inharmonic (deviant stimulus) to be significant across both groups following 33,37 , and $39 \mathrm{~Hz}$ entrainment, consistent with the finding that the RT differences between the harmonic and inharmonic targets reached significance for these entainment conditions (see Figure 3 ). Sources were located in the left hippocampus and parahippocampus $(33 \mathrm{~Hz})$, right superior frontal gyrus (SFG) $(37 \mathrm{~Hz})$, and the left inferotemporal gyrus (ITG) $(39 \mathrm{~Hz})$. In line with significant RT differences, the source of these harmonic ERF differences following 33 , and $39 \mathrm{~Hz}$ entrainment only remained significant for non-musicians, when the data were analysed separately per group (see Figure 4).

The right SFG has been associated with efficient response inhibition, characterising the neural processes associated with estimating likelihood - referred to as conflict anticipation (Hu, Ide, Zhang, $\& \mathrm{Li}, 2016)$. Furthermore, activation of this brain region has been implicated in improved auditory working memory performance (Othman et al., 2019). Thus, activation of the right SFG following $37 \mathrm{~Hz}$ entrainment suggests that the effect of priming at this rate facilitates response inhibition, and overall performance, for both groups. While grey matter density of the hippocampus has been found to be higher for musicians and musical expertise induces hippocampal structural and functional plasticity (M Groussard et al., 2009; Mathilde Groussard et al., 2010; Herdener et al., 2010), the hippocampus has also been found to be involved in novelty detection (Kumaran \& Maguire, 2007a, 2007b). Operating as a comparator, the hippocampus generates a response when the incoming stimulus violates predictions based on previous learning. Moreover, hippocampal activity is related to detection of novel configurations of familiar items - referred to as associative novelty (Kumaran \& Maguire, 2007a). Furthermore, activation of the left ITG among non-musicians following $39 \mathrm{~Hz}$ entrainment is possibly related to the contrast between the inharmonic and harmonic auditory stimuli given this area of cortex similarly exhibits increased activation in response to pseudowords compared to words (Binder, 2000; Specht \& Reul, 2003). The rationale for a contrast related response is based on the consideration that non-musicians process the pip-trains based on the contrast between the tones, rather than the harmony relations.

Critically, a source level ERF difference following $33 \mathrm{~Hz}$ stimulus entrainment uncovered differences in source activation strengths for each group - in separate locations, thus, highlighting a differential effect of priming on functional connectivity that is dependent on music training. For nonmusicians the source remained located in the left hippocampus and parahippocampus regions consistent with the enhanced ERF difference between source activations in response to the inharmonic compared to the harmonic found for this group alone, following $33 \mathrm{~Hz}$ stimulus entrainment (see Figure 5). For musicians the location of the increased difference ERF was in the left middle frontal gyrus (MFG) (see Figure 6). As discussed, hippocampal activation relates to novelty detection. Specifically, left hemispheric hippocampal activity occurs when one component of a familiar sequence is novel, while another is repeated (Kumaran \& Maguire, 2007a). In the context of the current paradigm, the implication is that for the musically naïve brain, $33 \mathrm{~Hz}$ entrainment facilitates a response to the inharmonic (a novel stimulus in an otherwise repeated sequence of pips). Musicians on the other hand, as a consequence of their training, have developed more efficient neural strategies, which may explain the increased activation originating in the left MFG for musicians compared to nonmusicians, observed following $33 \mathrm{~Hz}$ entrainment. The right MFG is associated with working memory 
bioRxiv preprint doi: https://doi.org/10.1101/2021.06.03.446932; this version posted June 3, 2021. The copyright holder for this preprint (which was not certified by peer review) is the author/funder, who has granted bioRxiv a license to display the preprint in perpetuity. It is made available under aCC-BY-NC-ND 4.0 International license.

processes and storage in general, with musicians showing increased activation compared to nonmusicians under increased load (Leung, Gore, \& Goldman-Rakic, 2002; Olesen, Westerberg, \& Klingberg, 2004; Pallesen et al., 2010). However, musicians have demonstrated enhanced functional connectivity across a neural network that spans between the left primary auditory cortex and the right globus palidus, bilateral motor areas and supramarginal gyri (SMG), left premotor cortex, and the left MFG (Fauvel et al., 2014). Thus, it is suggested that the $33 \mathrm{~Hz}$ entrainment improves musicians' recruitment of learning induced working memory neural strategies.

Our source level analysis suggests functional differences in auditory cognition between musicians and non-musicians are separable through an examination of differences in the effect of priming. Notably, stimulus entrainment appears to directly facilitate non-musicians' responses to the primed stimuli, whereas the only benefit of entrainment for musicians is suggested to be through an enhancement of an existing, training induced, functional connectivity network. Further support for this interpretation was provided by the frequency power analysis and the phase-amplitude coupling analysis. Stimulus entrainment entails driving brain oscillations using an external periodic force and is characterised by the adjustment of phase to the external stimulus (phase-locking) and an increase in amplitude among participating neurons (Thut, 2011). Therefore, an amplification of entrainment frequencies in auditory cortex was examined by plotting the spectrogram, covering the range of entrainment frequencies, during the $100 \mathrm{~ms}$ period between entrainment and target presentation. Consistent with stimulus entrainment, following 31,33 , and $37 \mathrm{~Hz}$ entrainment, the anticipated peak in the corresponding frequency was evident in the spectrogram for non-musicians. However, the spectrograms of musicians presented a much more complicated pattern of frequencies for each entrainment condition that imply an effect of a $9 \mathrm{~Hz}$ modulation during the 31 and $33 \mathrm{~Hz}$ entrainment conditions (see Figure 7). Furthermore, a phase-amplitude 8-9 Hz modulation effect was found consistently for musicians, in terms of the percentage of the group for whom the effect was significant, as well as across all conditions. The range and consistency of the phase-amplitude coupling evident for the non-musicians fluctuates in contrast.

Notably, the $7 \mathrm{~Hz}$ phase modulation of gamma amplitude across the full range, was found to be significant for between 27 and 33\% of non-musicians following $33 \mathrm{~Hz}$ entrainment (see Figure 8). The first research using the current auditory priming paradigm, and previous research using a functionally similar visual priming paradigm which used rates of flicker to evoke a phase locked cortical frequency response, have consistently supported the suggestion that an effect of priming, i.e., faster reaction-time responses following specific entrainment rates, depended on a phase interaction with a slower endogenous theta rhythm, of $6.69 \mathrm{~Hz}$ (see Elliott \& Müller, 1998 for details of the visual priming paradigm) (Aksentijevic et al., 2011; Elliott, 2014; Elliott \& du Bois, 2017; Elliott \& Müller, 2004; Elliott \& Müller, 1998). The results reported here represent the first evidence at the cortical level in support of this inference. The accumulated evidence from the source analyses, the frequency power spectrograms, and the PAC analyses infer a reduced effect of stimulus entrainment for musicians that stems from a greater reliance on the modulation effects of spontaneous theta and alpha on gamma-band synchronisation, rather than the early entrainment of gamma-band information carriers. In other words, musicians have developed top-down neural strategies that supersede the effects of stimulus entrainment - consistent with previous support for the redundancy of gamma-band oscillatory influence on musicians' performance due to experience-dependent plasticity (Headley \& Weinberger, 2011). 
bioRxiv preprint doi: https://doi.org/10.1101/2021.06.03.446932; this version posted June 3, 2021. The copyright holder for this preprint (which was not certified by peer review) is the author/funder, who has granted bioRxiv a license to display the preprint in perpetuity. It is made available under aCC-BY-NC-ND 4.0 International license.

The selection of relevant sensory input requires theta modulated synchronised gammanetworks, whereby cycles of spontaneous theta make and break the synchronised gamma oscillations through a process of phase reset (Fries, 2009; Rollenhagen \& Olson, 2005). Research has revealed that neurons in the IT cortex of monkeys respond selectively to a preferred visual stimulus from a display of multiple stimuli through this alternating pattern of rhythmic theta modulation, characterised by an increase in firing rate in response to a preferred stimulus and a decrease in firing rate in response to a non-preferred stimulus (Rollenhagen \& Olson, 2005). Moreover, the firing rate was enhanced when the preferred stimulus was presented in the presence of the non-preferred stimulus - interesting given the 2000 and $2400 \mathrm{~Hz}$ tones of the harmonic and inharmonic targets in the current research were presented simultaneously with the baseline $1000 \mathrm{~Hz}$ tones. In the context of this research a further relevant consideration has been suggested by Fries (2009), which is that this rhythmic response to the preferred stimulus was consistent with a $5 \mathrm{~Hz}$ theta oscillation, allowing for the selection of a response every $200 \mathrm{~ms}(1000 / 5=200)$, and therefore when two stimuli need to be discriminated, a selection is required every $100 \mathrm{~ms}$, corresponding with a $10 \mathrm{~Hz}$ alpha rhythm, also found to modulate gammaband synchronisation (Fries, 2009). While the IT cortex is critical for visual object recognition, as previously noted activity in IT has also been associated with contrast recognition in the auditory domain (Binder, 2000; Specht \& Reul, 2003).

Although the thalamus is fundamentally involved in the generation of alpha (Roux, Wibra, Singer, Aru, \& Uhlhaas, 2013), with theta generation occurring in the hippocampus and hippocampal structures, (Pignatelli, Beyeler, \& Leinekugel, 2012), alpha has also been recorded in the hippocampus and theta in the frontal cortex (Buffalo, Fries, Landman, Buschman, \& Desimone, 2011; Roux \& Uhlhaas, 2014) - and both have been associated with working memory (WM). According to the shortterm memory model proposed by Horn and Usher (1992), stimulus information is carried forward within a synchronised gamma-band oscillatory network, with sequential stimuli coded by sequential gamma subcycles. These subcycles are nested in each theta cycle, allowing sequence order to be coded and stored in short-term memory, which is supported by the well-established $7 \pm 2$ short-term memory capacity limit (Horn \& Usher, 1992; Jensen \& Lisman, 2005). Furthermore, whereas thetagamma modulation is involved in WM item maintenance, alpha-gamma modulation has been found to protect items in WM through the inhibition of non-relevant information (Roux \& Uhlhaas, 2014). Interestingly, theta phase modulation of alpha amplitude has been found to be involved in attending to multiple items simultaneously (Song, Meng, Lin, Zhou, \& Luo, 2014). Furthermore, enhanced theta activity has been demonstrated to be associated with prediction, i.e. when a prime accurately predicts a response (Dikker \& Pylkkänen, 2013). These frequency interactions, taken together with the enhanced ERF difference for inharmonic targets following a $37 \mathrm{~Hz}$ entrainment frequency, highlight an important effect of priming that spans both groups - that is, rather than facilitating auditory cognitive processes alone, priming at some entrainment frequencies yields an enhancement of cognitive processes elicited by task demands, i.e., the requirement to make a forced-choice response, as quickly as possible, based on the tonal difference between two targets. However, it is important to note, that real-world auditory cognition does require selective and sustained attention, which in turn requires inhibition of irrelevant information - and importantly, to navigate effectively and interact with the environment, auditory cognition (and cognition in general) requires the ability to correctly predict events as they unfold. This latter requirement is fundamental to a musician's ability to synchronise their performance with other musicians. 
It is also worth noting, within the auditory cortex nested oscillations are hierarchically organised such that the phase of $1-4-\mathrm{Hz}$ neural oscillators modulate the amplitude of $4-10-\mathrm{Hz}$ neural oscillators, which in turn modulate gamma amplitude $(30-50 \mathrm{~Hz})$, thus optimising the system's ability to process rhythm through structuring the pattern of temporal activity (Lakatos et al., 2005). Thus, in tandem with the benefits associated with the modulation effects of spontaneous brain rhythms on cognition in general, auditory cognition relies on this hierarchy of interactions to track and separate sound objects. Furthermore, it has been argued that sensory and cognitive events evoke superimposed delta, theta, alpha, and gamma oscillatory mechanisms, within selectively distributed networks, varying in intensity, synchronisation, delay and duration, depending on functional demands (Başar, Başar-Eroglu, Karakaş, \& Schürmann, 2001).

\section{Conclusion}

In summary, while both groups exhibit behavioural (RT) and ERF activity related to priming an auditory response using stimulus entrainment presented at entrainment frequencies of $33 \mathrm{~Hz}, 37 \mathrm{~Hz}$, and 39 $\mathrm{Hz}$ - there was a disparity in the outcome of this effect dependent on music ability which was found to reflect functional differences in auditory cognition as a consequence of music training. Notably, non-musicians demonstrated a direct enhancement in working memory processes and ability to detect a deviant auditory stimulus, whereas the effect for musicians reflected improved functional connectivity, emphasised by consistent theta and alpha phase modulation of gamma amplitude, presumably due to the plasticity effects of music training. These slower endogenous frequencies are relied upon for feedback predictions, e.g. inhibiting irrelevant information (via alpha rhythms) and manipulating information (via theta rhythms) (Kirmizi-Alsan et al., 2006; Roux \& Uhlhaas, 2014; Sauseng, Griesmayr, Freunberger, \& Klimesch, 2010; Sauseng et al., 2009). Thus, it is concluded from the findings of this research that musicians' response to the harmonic structure of a sound depends more on top-down processing (greater range of interactions with slower brain rhythms) than bottomup processing (gamma rhythms) provided by the entrained prime, found to facilitate the responses of non-musicians.

\section{Limitations and future research}

The current analysis provides motivating information regarding the utility of stimulus entrainment in an examination of differences in auditory cognitive processes dependent on musical ability. However, further analysis is recommended using a larger sample to improve the power of the statistical findings. Recent literature examining structural and functional differences between musicians and nonmusicians using MEG have generally had a sample size of 15, and up to 26, per group. A power analysis for an effect size of 0.25 , at $80 \%$ power, advises 17 per group. Thus, the current study was underpowered. Furthermore, towards a more complete understanding of the importance of gamma frequency-specific effects on auditory cognition, a wider range of entrainment frequencies should be employed. A further consideration that has been highlighted here is the effect of music training type. It would be interesting to employ the same design using a sample of jazz musicians to compare the results. Regarding the range of expertise within the current sample, varying from grade 3 to professional - this represents a further limitation which should be addressed in future work. 
bioRxiv preprint doi: https://doi.org/10.1101/2021.06.03.446932; this version posted June 3, 2021. The copyright holder for this preprint (which was not certified by peer review) is the author/funder, who has granted bioRxiv a license to display the preprint in perpetuity. It is made available under aCC-BY-NC-ND 4.0 International license.

\section{Acknowledgements}

This work was supported by an Irish Research Council scholarship to the first author (project ID: GOIPG/2015/1678), and in part by the Northern Ireland Functional Brain Mapping (NIFBM) Facility Project through Invest Northern Ireland (Invest NI) and the Ulster University under Grant 1303/101154803. We thank Dr Pramod Gaur (Ulster University, Magee campus, Derry) for assisting in data collection, Dr Tamas Minarik and Prof Paul Sauseng (Ludwig-Maximilians-Universität Munich) for contributing to the analysis codes, and $\mathrm{Dr}$ Bernadette C. M. van Wijk for advising on the phaseamplitude coupling analysis (The Wellcome Trust Centre for Neuroimaging, UCL, London).

\section{Data availability statement}

The data that support the findings of this study are available from the corresponding author upon reasonable request. 

made available under aCC-BY-NC-ND 4.0 International license.

\section{Table of Figures}

Figure 1. Trial sequence for an inharmonic target in the $33 \mathrm{~Hz}$ entrainment condition. The entrainer pip-train for all conditions comprised a repeated pattern of four 'pips'; one pip with a CF of $1000 \mathrm{~Hz}$ (the deviant tone; D) followed by three pips with CFs of $500 \mathrm{~Hz}$ (baseline tones; B). The target-absent pip-train for all conditions carried only $1000 \mathrm{~Hz}$ pips, while the harmonic- and inharmonic-target piptrains were composed of an alternating pattern of two pips; the CFs of the alternating pips were $1000 \mathrm{~Hz}(B)$ and $2000 \mathrm{~Hz}$ (D) in the harmonic target pip-train, and $1000 \mathrm{~Hz}$ (B) and $2400 \mathrm{~Hz}$ (D) in the inharmonic target pip-train. The amplitude modulation frequency in the above example was $33 \mathrm{~Hz}-$ therefore, the 1000 ms entrainment period ended following a deviant pip in the repeated pattern of four pips (DBBB)......

Figure 2. Differences in average reaction times (RTs) between harmonic and inharmonic responses, for each entrainment condition and group. Averaged harmonic RT responses subtracted from averaged inharmonic RT responses for musicians (red bar) and non-musicians (blue bar) for entrainment frequency condition ( $x$-axis). Pairwise comparison found faster responses to inharmonics following $33 \mathrm{~Hz}, 37 \mathrm{~Hz}$, and $39 \mathrm{~Hz}$ entrainment $\left({ }^{*}\right)$, while pairwise comparison of all three factors (group, target and entrainment frequency) revealed the RT difference remained significant for non-musicians only following $33 \mathrm{~Hz}$ and $39 \mathrm{~Hz}$ entrainment (triangles).

Figure 3. Mean images depicting the MEG source localisation of the difference between harmonic and inharmonic ERF activation, 350 ms post-stimulus onset (time window = [325 - $375 \mathrm{~ms}]$ ), for musicians and non-musicians combined, following entrainment frequencies of (a) $33 \mathrm{~Hz}$, (b) $37 \mathrm{~Hz}$, and (c) $39 \mathrm{~Hz}$. For each condition, the source location is presented in (1) coronal (2) sagittal and (3) transverse views. Source activities identified: (a) left hippocampus and parahippocampal area (MNI coordinates [-16 -30 -12] mm), following $33 \mathrm{~Hz}$ entrainment; (b) right superior frontal cortex (MNI coordinates [20 16 56] mm), following $37 \mathrm{~Hz}$ entrainment; and (c) left inferior temporal lobe (MNI coordinates [- 42 - 38 - 12] mm), following $39 \mathrm{~Hz}$ entrainment. Values plotted are the cluster tstatistics within the range -5 to 5 (see colour bar), with significant clusters $(p<.05)$ marked by the crosshair.

Figure 4. Mean images depicting the source localisation of the difference between harmonic and inharmonic ERF activation, $\sim 350 \mathrm{~ms}$ post-stimulus onset (time window $=[325-375 \mathrm{~ms}]$ ), following entrainment frequencies of (a) $33 \mathrm{~Hz}$ and (b) $39 \mathrm{~Hz}$, for the non-musician group. For each condition, the source location is presented in (1) coronal (2) sagittal and (3) transverse views. As for the combined data under the same entrainment conditions, $(a, 33 \mathrm{~Hz})$ is located in the left hippocampus and parahippocampal area (MNI coordinates [-16-30 -12] mm), and (b, $39 \mathrm{~Hz})$ in the left inferior temporal lobe (MNI coordinates [- 42 - 38 - 12] mm). Values plotted are the cluster t-statistics within the range -5 to 5 (see colour bar), with significant clusters $(p<.05)$ marked by the crosshair. .10

Figure 5. Mean image depicting the source localisation for the inharmonic-harmonic difference ERF activation showing a significant increase in strength for the musician group following $33 \mathrm{~Hz}$ entrainment, when an alpha threshold of 0.01 was applied. Location: left middle frontal gyrus (MNI coordinates [- 4244 18] mm), 350 ms post stimulus onset, displayed in (1) coronal (2) sagittal and (3) transverse views. Values plotted are the cluster t-statistics within the range -5 to 5 (see colour bar), with significant clusters $(p<.01)$ marked by the crosshair.

Figure 6. Mean image depicting the source localisation for the inharmonic-harmonic difference ERF activation showing a significant increase in strength for the non-musician group following $33 \mathrm{~Hz}$ 
entrainment. An alpha threshold of 0.01 used. Location: left parahippocampal and left fusiform gyri (MNI coordinates [- $22-38$-12] mm), 350 ms post stimulus onset, displayed in (1) coronal (2) sagittal and (3) transverse views. Values plotted are the cluster t-statistics within the range -5 to 5 (see colour bar), with significant clusters $(p<.01)$ marked by the crosshair.

Figure 7. Frequency power spectral analysis during the $100 \mathrm{~ms}$ interval between entrainer offset and target onset. (a) Musician; (b) non-musician. Bandpass filtered between 28 and $42 \mathrm{~Hz}$. Legend: Each entrainment condition. Frequency $(\mathrm{Hz})$ is presented on the $\mathrm{x}$-axis and amplitude $(\mu \mathrm{V})$ is presented on the $y$-axis.

Figure 8. Grand-averaged PAC spectral densities for musicians and non-musicians during the $33 \mathrm{~Hz}$ entrainment condition (top left corner). (a) Grand-averaged PAC values for each gamma and slow wave frequency combination in the spectrum. (b) Percentage cases with significant PAC (white; $p<$ 0.01 , and grey; $p<0.05$ ) for each gamma and slow wave frequency combination in the spectrum. (c) and (d) Spectral densities for 'musicians' (red legend) and 'non-musicians' (blue legend). .16

Figure 9. Grand-averaged PAC spectral densities for musicians and non-musicians during the $37 \mathrm{~Hz}$ entrainment condition (top left corner). (a) Grand-averaged PAC values for each gamma and slow wave frequency combination in the spectrum. (b) Percentage cases with significant PAC (white; $p<$ 0.01 , and grey; $p<0.05$ ) for each gamma and slow wave frequency combination in the spectrum. (c) and (d) Spectral densities for 'musicians' (red legend) and 'non-musicians' (blue legend).

Figure 10. Grand-averaged PAC spectral densities for musicians and non-musicians during the $39 \mathrm{~Hz}$ entrainment condition (top left corner). (a) Grand-averaged PAC values for each gamma and slow wave frequency combination in the spectrum. (b) Percentage cases with significant PAC (white; $p<$ 0.01 , and grey; $p<0.05$ ) for each gamma and slow wave frequency combination in the spectrum. (c) and (d) Spectral densities for 'musicians' (red legend) and 'non-musicians' (blue legend). 


\section{References}

Aksentijevic, A., Barber, P. J., \& Elliott, M. A. (2011). Process Timing and Its Relation to the Coding of Tonal Harmony. Journal of Experimental Psychology: Human Perception and Performance, 37(5), 1628-1642. https://doi.org/10.1037/a0023112

Aksentijevic, A., Northeast, A., Canty, D., \& Elliott, M. A. (2013). The oscillatory entrainment of virtual pitch perception. Frontiers in Psychology, 4(210). https://doi.org/10.3389/fpsyg.2013.00210

Aksentijevic, A., Smith, A., \& Elliott, M. A. (2014). Rate-specific Entrainment of Harmonic Pitch. Music Perception: An Interdisciplinary Journal, 31(4), 316-322.

https://doi.org/10.1525/mp.2014.31.4.316

Angulo-Perkins, A., Aub, W., Peretz, I., Barrios, F. A., Armony, J. L., \& Concha, L. (2014). Music listening engages specific cortical regions within the temporal lobes: Differences between musicians and non-musicians. Cortex, 59, 126-137.

https://doi.org/10.1016/j.cortex.2014.07.013

Ashburner, J. (2007). A fast diffeomorphic image registration algorithm. https://doi.org/10.1016/j.neuroimage.2007.07.007

Başar, E., Başar-Eroglu, C., Karakaş, S., \& Schürmann, M. (2001). Gamma, alpha, delta, and theta oscillations govern cognitive processes. International Journal of Psychophysiology, 39(2-3), 241-248. https://doi.org/10.1016/S0167-8760(00)00145-8

Binder, J. R. (2000). Human Temporal Lobe Activation by Speech and Nonspeech Sounds. Cerebral Cortex, 10(5), 512-528. https://doi.org/10.1093/cercor/10.5.512

Bubic, A., Yves von Cramon, D., \& Schubotz, R. I. (2010). Prediction, cognition and the brain. Frontiers in Human Neuroscience, 4(25). https://doi.org/10.3389/fnhum.2010.00025

Buffalo, E. A., Fries, P., Landman, R., Buschman, T. J., \& Desimone, R. (2011). Laminar differences in gamma and alpha coherence in the ventral stream. Proceedings of the National Academy of Sciences of the United States of America, 108(27), 11262-11267. https://doi.org/10.1073/pnas.1011284108

Dikker, S., \& Pylkkänen, L. (2013). Predicting language: MEG evidence for lexical preactivation. Brain and Language, 127, 55-64. https://doi.org/10.1016/j.bandl.2012.08.004

du Bois, N., \& Elliott, M. A. (2017). The temporal dynamics involved in object representation updating to predict change. In Progress in Brain Research (1st ed., Vol. 236).

https://doi.org/10.1016/bs.pbr.2017.06.009

Elliott, M. A., \& du Bois, N. (2017). Dynamical constants and time universals: A first step toward a metrical definition of ordered and abnormal cognition. Frontiers in Psychology, 8. https://doi.org/10.3389/fpsyg.2017.00332

Elliott, Mark A. (2014). Atemporal equilibria: Pro- and retroactive coding in the dynamics of cognitive microstructures. Frontiers in Psychology, 5(990). https://doi.org/10.3389/fpsyg.2014.00990

Elliott, Mark A., \& du Bois, N. (2017). Dynamical Constants and Time Universals: A First Step toward a Metrical Definition of Ordered and Abnormal Cognition. Frontiers in Psychology, 8, 332. https://doi.org/10.3389/fpsyg.2017.00332

Elliott, Mark A., \& Müller, H. J. (2004). Synchronization and stimulus timing: Implications for temporal models of visual information processing. In C. Kaernbach, E. Schröger, \& H. Müller (Eds.), Psychophysics Beyond Sensation: Laws and Invariants of Human Cognition (pp. 137- 

made available under aCC-BY-NC-ND 4.0 International license.

156). https://doi.org/10.4324/9781410610744

Elliott, Mark A, \& Müller, H. J. (1998). Synchronous Information Presented in 40-Hz Flicker Enhances Visual Feature Binding. Psychological Science, 9(4), 277-283. Retrieved from http://www.jstor.org/stable/40063337

Engel, A. K., Fries, P., \& Singer, W. (2001). Dynamic predictions: Oscillations and synchrony in topdown processing. Nature Reviews Neuroscience, 2(10), 704-716. https://doi.org/10.1038/35094565

Fauvel, B., Groussard, M., Chételat, G., Fouquet, M., Landeau, B., Eustache, F., ... Platel, H. (2014). Morphological brain plasticity induced by musical expertise is accompanied by modulation of functional connectivity at rest. Neurolmage, 90(January), 179-188.

https://doi.org/10.1016/j.neuroimage.2013.12.065

Fries, P. (2009). Neuronal Gamma-Band Synchronization as a Fundamental Process in Cortical Computation. Annual Review of Neuroscience, 32(1), 209-224. https://doi.org/10.1146/annurev.neuro.051508.135603

Fries, P. (2015). Rhythms for Cognition: Communication through Coherence. Neuron, Vol. 88, pp. 220-235. https://doi.org/10.1016/j.neuron.2015.09.034

Gaab, N., \& Schlaug, G. (2003). The effect of musicianship on pitch memory in performance matched groups. Neuroreport, 14(18), 2291-2295. https://doi.org/10.1097/01.wnr.0000093587.33576.f7

Galambos, R., Makeig, S., \& Talmachoff, P. J. (1981). A 40-Hz auditory potential recorded from the human scalp. Proceedings of the National Academy of Sciences, 78(4), 2643-2647. https://doi.org/10.1073/pnas.78.4.2643

Galambos, Robert. (1992). A Comparison of Certain Gamma Band (40-HZ) Brain Rhythms in Cat and Man. In A. E.Basar \& T.M.Bullock (Eds.), Induced Rhythms in the Brain (pp. 201-216). https://doi.org/10.1007/978-1-4757-1281-0_11

Gaser, C., \& Schlaug, G. (2003). Brain Structures Differ between Musicians and Non-Musicians. The Journal of Neuroscience, 23(27), 9240-9245. Retrieved from http://www.jneurosci.org/content/jneuro/23/27/9240.full.pdf

Groussard, M, Rauchs, G., Landeau, B., Viader, F., Dayan, J., Desgranges, B., ... Platel, H. (2009). The neural correlates of musical and verbal semantic memory assessed by fMRI. Neurolmage, 47(March 2018), S53. https://doi.org/10.1016/s1053-8119(09)70165-x

Groussard, Mathilde, La Joie, R., Rauchs, G., Landeau, B., Chételat, G., Viader, F., ... Platel, H. (2010). When music and long-term memory interact: Effects of musical expertise on functional and structural plasticity in the hippocampus. PLOS ONE, 5(10), 1-8.

https://doi.org/10.1371/journal.pone.0013225

Headley, D. B., \& Weinberger, N. M. (2011). Gamma-band activation predicts both associative memory and cortical plasticity. The Journal of Neuroscience : The Official Journal of the Society for Neuroscience, 31(36), 12748-12758. https://doi.org/10.1523/JNEUROSCI.2528-11.2011

Herdener, M., Esposito, F., di Salle, F., Boller, C., Hilti, C. C., Habermeyer, B., ... Cattapan-Ludewig, K. (2010). Musical training induces functional plasticity in human hippocampus. J Neurosci, 30(4), 1377-1384. https://doi.org/10.1523/JNEUROSCI.4513-09.2010

Horn, D., \& Usher, M. (1992). Oscillatory model of short term memory. Advances in Neural Information Processing Systems, 4(1990), 125-132. 
Hu, S., Ide, J. S., Zhang, S., \& Li, C. S. R. (2016). The right superior frontal gyrus and individual variation in proactive control of impulsive response. Journal of Neuroscience, 36(50), 1268812696. https://doi.org/10.1523/JNEUROSCI.1175-16.2016

Jensen, O., \& Lisman, J. E. (2005). Hippocampal sequence-encoding driven by a cortical multi-item working memory buffer. Trends in Neurosciences, 28(2), 67-72. https://doi.org/10.1016/j.tins.2004.12.001

Justus, T., \& Bharucha, J. (2002). Music perception and cognition. In Stevens' Handbook of Experimental Psychology (Vol. 1, pp. 453-492). https://doi.org/10.1002/0471214426

Kirmizi-Alsan, E., Bayraktaroglu, Z., Gurvit, H., Keskin, Y. H., Emre, M., \& Demiralp, T. (2006). Comparative analysis of event-related potentials during Go/NoGo and CPT: Decomposition of electrophysiological markers of response inhibition and sustained attention. Brain Research, 1104(1), 114-128. https://doi.org/10.1016/j.brainres.2006.03.010

Koelsch, S. (2011). Toward a neural basis of music perception - a review and updated model. Frontiers in Psychology, 2. https://doi.org/10.3389/fpsyg.2011.00110

Koelsch, S., \& Mulder, J. (2002). Electric brain responses to inappropriate harmonies during listening to expressive music. Clinical Neurophysiology, 113, 862-869. Retrieved from https://ac.elscdn.com/S1388245702000500/1-s2.0-S1388245702000500-main.pdf?_tid=66ecc2e5-d1ef4780-bc53-6abc9d6d8d5c\&acdnat=1531419592_554c341ff482a8a75164afa1c3e03635

Kumaran, D., \& Maguire, E. A. (2007a). Match-mismatch processes underlie human hippocampal responses to associative novelty. Journal of Neuroscience, 27(32), 8517-8524. https://doi.org/10.1523/JNEUROSCI.1677-07.2007

Kumaran, D., \& Maguire, E. A. (2007b). Which Computational Mechanisms Operate in the Hippocampus During Novelty Detection? Hippocampus, 17(9), 735-748. https://doi.org/10.1002/hipo

Lakatos, P., Shah, A. S., Knuth, K. H., Ulbert, I., Karmos, G., \& Schroeder, C. E. (2005). An oscillatory hierarchy controlling neuronal excitability and stimulus processing in the auditory cortex. Journal of Neurophysiology, 94(3), 1904-1911. https://doi.org/10.1152/jn.00263.2005

Leung, H. C., Gore, J. C., \& Goldman-Rakic, P. S. (2002). Sustained mnemonic response in the human middle frontal gyrus during on-line storage of spatial memoranda. Journal of Cognitive Neuroscience, 14(4), 659-671. https://doi.org/10.1162/08989290260045882

Litvak, V., Mattout, J., Kiebel, S., Phillips, C., Henson, R., Kilner, J., ... Friston, K. (2011). EEG and MEG data analysis in SPM8. Computational Intelligence and Neuroscience, 2011. https://doi.org/10.1155/2011/852961

Maess, B., Koelsch, S., Gunter, T. C., \& Friederici, A. (2001). Musical syntax is processed in the area of Broca: an MEG study. Neurolmage, 11(5), S56-S56. https://doi.org/10.1016/S10538119(00)90990-X

Michalareas, G., Vezoli, J., van Pelt, S., Schoffelen, J.-M., Kennedy, H., \& Fries, P. (2016). Alpha-Beta and Gamma Rhythms Subserve Feedback and Feedforward Influences among Human Visual Cortical Areas. Neuron, 89(2), 384-397. https://doi.org/10.1016/j.neuron.2015.12.018

Olesen, P. J., Westerberg, H., \& Klingberg, T. (2004). Increased prefrontal and parietal activity after training of working memory. Nature Neuroscience, 7(1), 75-79. https://doi.org/10.1038/nn1165

Oostenveld, R., Fries, P., Maris, E., \& Schoffelen, J. M. (2011). FieldTrip: Open source software for 

made available under aCC-BY-NC-ND 4.0 International license.

advanced analysis of MEG, EEG, and invasive electrophysiological data. Computational Intelligence and Neuroscience. https://doi.org/10.1155/2011/156869

Othman, E. A., Yusoff, A. N., Mohamad, M., Abdul Manan, H., Abd Hamid, A. I., \& Giampietro, V. (2019). Hemispheric Lateralization of Auditory Working Memory Regions During Stochastic Resonance: An fMRI Study. Journal of Magnetic Resonance Imaging, 1-8. https://doi.org/10.1002/jmri.27016

Pallesen, K. J., Brattico, E., Bailey, C. J., Korvenoja, A., Koivisto, J., Gjedde, A., \& Carlson, S. (2010). Cognitive control in auditory working memory is enhanced in musicians. PLOS ONE, 5(6). https://doi.org/10.1371/journal.pone.0011120

Pantev, Christo, \& Elbert, T. (1994). The Transient Auditory Evoked Gamma-Band Field. In C. Pantev (Ed.), Oscillatory Event-Related Brain Dynamics (pp. 219-230). https://doi.org/10.1007/978-14899-1307-4_16

Patel, A. D., Gibson, E., Ratner, J., Besson, M., \& Holcomb, P. J. (1998). Processing syntactic relations inlanguage and music: an event-related potential study. J Cog Neurosci, 10(6), 717-733. https://doi.org/10.1162/089892998563121

Penny, W. D., Duzel, E., Miller, K. J., \& Ojemann, J. G. (2008). Testing for nested oscillation. Journal of Neuroscience Methods, 174, 50-61. https://doi.org/10.1016/j.jneumeth.2008.06.035

Pi, Y. L., Wu, X. H., Wang, F. J., Liu, K., Wu, Y., Zhu, H., \& Zhang, J. (2019). Motor skill learning induces brain network plasticity: A diffusion-tensor imaging study. PLOS ONE, 14(2), 1-17. https://doi.org/10.1371/journal.pone.0210015

Pignatelli, M., Beyeler, A., \& Leinekugel, X. (2012). Neural circuits underlying the generation of theta oscillations. Journal of Physiology Paris, 106(3-4), 81-92. https://doi.org/10.1016/j.jphysparis.2011.09.007

Rohrmeier, M. A., \& Koelsch, S. (2012). Predictive information processing in music cognition. A critical review. International Journal of Psychophysiology, 83(2), 164-175. https://doi.org/10.1016/j.ijpsycho.2011.12.010

Rollenhagen, J. E., \& Olson, C. R. (2005). Low-frequency oscillations arising from competitive interactions between visual stimuli in macaque inferotemporal cortex. Journal of Neurophysiology, 94(5), 3368-3387. https://doi.org/10.1152/jn.00158.2005

Rosenberg-Lee, M., luculano, T., Bae, S. R., Richardson, J., Qin, S., Jolles, D., \& Menon, V. (2018). Short-term cognitive training recapitulates hippocampal functional changes associated with one year of longitudinal skill development. Trends in Neuroscience and Education, 10(June 2017), 19-29. https://doi.org/10.1016/j.tine.2017.12.001

Roux, F., \& Uhlhaas, P. J. (2014). Working memory and neural oscillations: Alpha-gamma versus theta-gamma codes for distinct WM information? Trends in Cognitive Sciences, 18(1), 16-25. https://doi.org/10.1016/j.tics.2013.10.010

Roux, F., Wibra, M., Singer, W., Aru, J., \& Uhlhaas, P. J. (2013). The phase of thalamic alpha activity modulates cortical gamma-band activity: Evidence from resting-state MEG recordings. Journal of Neuroscience, 33(45), 17827-17835. https://doi.org/10.1523/JNEUROSCI.5778-12.2013

Sauseng, P., Griesmayr, B., Freunberger, R., \& Klimesch, W. (2010). Control mechanisms in working memory: A possible function of EEG theta oscillations. Neuroscience and Biobehavioral Reviews, 34(7). https://doi.org/10.1016/j.neubiorev.2009.12.006

Sauseng, P., \& Klimesch, W. (2008). What does phase information of oscillatory brain activity tell us 
about cognitive processes? Neuroscience and Biobehavioral Reviews, Vol. 32, pp. 1001-1013. https://doi.org/10.1016/j.neubiorev.2008.03.014

Sauseng, P., Klimesch, W., Heise, K. F., Gruber, W. R., Holz, E., Karim, A. A., ... Hummel, F. C. (2009). Brain Oscillatory Substrates of Visual Short-Term Memory Capacity. Current Biology, 19(21), 1846-1852. https://doi.org/10.1016/j.cub.2009.08.062

Scheffer-Teixeira, R., Belchior, H., Caixeta, F. V., Souza, B. C., Ribeiro, S., \& Tort, A. B. L. (2012). Theta phase modulates multiple layer-specific oscillations in the CA1 region. Cerebral Cortex, 22(10), 2404-2414. https://doi.org/10.1093/cercor/bhr319

Schlaug, G., Jäncke, L., Huang, Y., Staiger, J. F., \& Steinmetz, H. (1995). Increased corpus callosum size in musicians. Neuropsychologia, 33(8), 1047-1055. https://doi.org/10.1016/00283932(95)00045-5

Schneider, P., Sluming, V., Roberts, N., Scherg, M., Goebel, R., Specht, H. J., ... Rupp, A. (2005). Structural and functional asymmetry of lateral Heschl's gyrus reflects pitch perception preference. Nature Neuroscience, 8(9), 1241-1247. https://doi.org/10.1038/nn1530

Schomburg, E. W., Fernández-Ruiz, A., Mizuseki, K., Berényi, A., Anastassiou, C. A., Koch, C., \& Buzsáki, G. (2014). Theta Phase Segregation of Input-Specific Gamma Patterns in EntorhinalHippocampal Networks. Neuron, 84(2), 470-485.

https://doi.org/10.1016/j.neuron.2014.08.051

Song, K., Meng, M., Lin, C., Zhou, K., \& Luo, H. (2014). Behavioral oscillations in attention: Rhythmic $\alpha$ pulses mediated through $\theta$ band. Journal of Neuroscience, 34(14), 4837-4844. https://doi.org/10.1523/JNEUROSCI.4856-13.2014

Specht, K., \& Reul, J. (2003). Functional segregation of the temporal lobes into highly differentiated subsystems for auditory perception: An auditory rapid event-related fMRI-task. Neurolmage, 20(4), 1944-1954. https://doi.org/10.1016/j.neuroimage.2003.07.034

Thut, G., Schyns, P. G., \& Gross, J. (2011). Entrainment of perceptually relevant brain oscillations by non-invasive rhythmic stimulation of the human brain. Frontiers in Psychology, 2(170), 1-10. https://doi.org/10.3389/fpsyg.2011.00170

Van Veen, B. D., Van Drongelen, W., Yuchtman, M., \& Suzuki, A. (1997). Localization of Brain Electrical Activity via Linearly Constrained Minimum Variance Spatial Filtering. In IEEE Transactions on Biomedical Engineering (Vol. 44). Retrieved from http://www.sci.utah.edu/ wolters/LiteraturZurVorlesung/Literatur/D:_InverseProblem/C:_Met hodsForNonCorrelatedSources/B:_Beamforming/A:_VanVeenDrongelenYuchtmanSuzuki_LCM V-SF_TBME_Sept_97.pdf

van Wijk, B. C.M., Jha, A., Penny, W., \& Litvak, V. (2015). Parametric estimation of cross-frequency coupling. Journal of Neuroscience Methods, 243, 94-102. https://doi.org/10.1016/j.jneumeth.2015.01.032

van Wijk, Bernadette C.M., Beudel, M., Jha, A., Oswal, A., Foltynie, T., Hariz, M. I., ... Litvak, V. (2016). Subthalamic nucleus phase-amplitude coupling correlates with motor impairment in Parkinson's disease. Clinical Neurophysiology, 127, 2010-2019. https://doi.org/10.1016/j.clinph.2016.01.015

Vuust, P., Brattico, E., Seppänen, M., Näätänen, R., \& Tervaniemi, M. (2012). The sound of music: Differentiating musicians using a fast, musical multi-feature mismatch negativity paradigm. Neuropsychologia, 50(7), 1432-1443. https://doi.org/10.1016/j.neuropsychologia.2012.02.028 
bioRxiv preprint doi: https://doi.org/10.1101/2021.06.03.446932; this version posted June 3, 2021. The copyright holder for this preprint (which was not certified by peer review) is the author/funder, who has granted bioRxiv a license to display the preprint in perpetuity. It is made available under aCC-BY-NC-ND 4.0 International license.

Zatorre, R. J., Chen, J. L., \& Penhune, V. B. (2007). When the brain plays music: Auditory-motor interactions in music perception and production. Nature Reviews Neuroscience, 8(7), 547-558. https://doi.org/10.1038/nrn2152 